\title{
Multi-sensor integrated Framework and Index for Agricultural Drought Monitoring
}

Xiang Zhanga,b, Nengcheng Chen ${ }^{\mathrm{a}, \mathrm{c}, *}$, Jizhen Li ${ }^{\mathrm{a}, \mathrm{d}}$, Zhihong Chena, Dev Niyogib,e aState Key Laboratory of Information Engineering in Surveying, Mapping, and Remote Sensing, Wuhan University, Wuhan 430079, China

bDepartment of Agronomy, Purdue University, West Lafayette, IN 47907, USA

${ }^{c}$ Collaborative Innovation Center of Geospatial Technology, Wuhan 430079, China dChongqing Planning \& Design Institute, Chongqing 401147, China eDepartment of Earth, Atmospheric, and Planetary Sciences, Purdue University, West Lafayette, IN 47907, USA

cnc@whu.edu.cn

Abstract: Agricultural drought is a complex and insidious natural hazard further complicated by crop impacts. Univariate, bivariate, and multivariate drought analyses have achieved some success, but the analysis of agricultural drought evolution and integration with crop growth is still lacking. In this study, an Evolution Process-based Multi-sensor Collaboration (EPMC) framework was proposed with the realization that effective agricultural drought assessment requires an integrated approach that considers both drought development and crop phenology. The Process-based Accumulated Drought Index (PADI) was designed to quantify the accumulative drought impacts on crops. Based on discrete monitoring of precipitation, soil moisture, and vegetation conditions, EPMC extracted four main agricultural drought evolution phases termed: (i) 
Latency, (ii) Onset, (iii) Development, and (iv) Recovery. Subsequently, the crop growth stages and water-deficit sensitivity coefficients were integrated with the drought evolution process. Experiments conducted in three different climate regions of China demonstrated that the EPMC framework could clearly depict evolution of the different phases of agricultural drought. Three decades of multi-sensor datasets include monthly precipitation from the Global Precipitation Climatology Centre (GPCC), root zone soil moisture from the satellite-model integrated Global Land Data Assimilation System version 2 (GLDAS-2.0), and vegetation condition data from the Advanced Very High Resolution Radiometer (AVHRR). Results indicated that PADI reliably provided a weekly evaluation of accumulative drought severity instead of a "snapshot". PADI was also compared with the Palmer Drought Severity Index (PDSI) and multi-time scale of Standardized Precipitation Index (SPI). Results showed good correlation with short-term SPI at the onset of drought as well as long-term SPI at later stages. Additionally, compared to the correlation with precipitation, soil moisture, and vegetation data alone, it was found that as an integrated model, PADI correlated well with wheat yield loss (Spearman rank correlation coefficient $\rho$ was between $0.66-0.77, \mathrm{p}<0.05)$. Therefore, this multi-sensor integrated monitoring framework and index provides a useful and new approach to address the complexity of agricultural drought, with particular relevance to drought impact assessment. 
Keywords: Agricultural drought; Drought evolution; Drought impact;

Multi-sensor collaboration; Multivariate drought index.

\section{Introduction}

Drought is a major natural hazard in China and all over the world (Wilhite, 2000; Sheffield et al., 2012; AghaKouchak et al., 2015a). For instance, the 2011 summer drought in China affected over 30 million people causing an economic loss of about 2.4 billion dollars (Yuan et al., 2015). Responding to need for drought monitoring and evaluation by remote sensing approach, this study seeks a multi-sensor collaboration approach to form a multivariate drought model.

Over the last decades, studies have described drought concepts (Dracup, 1991; Wilhite, 1993), monitoring (Svoboda et al., 2002; AghaKouchak et al., 2015b), predictions (Hunt, 1991), impacts (Changnon and Easterling, 1989; Mallya et al., 2013), Vulnerability (Charusombat and Niyogi, 2011), and mitigation (Wilhite et al., 2007). A number of drought information systems have been configured to display and integrate drought indices more intuitively. From global to regional scales, examples include Global Integrated Drought Monitoring and Prediction System (GIDMaPS; Hao et al., 2014), Global Drought Information System (GDIS; Heim and Brewer, 2012), Standardized Precipitation-Evapotranspiration Index (SPEI) Global Drought Monitor (Beguería et al., 2010), African Flood and Drought Monitor (AFDM; Yuan et al., 2013; Sheffield et al., 2014), Famine Early Warning System Network in Africa (FEWS NET; Verdin et al., 2005), US-Mexico Drought Prediction Tool (Lyon et al., 2012), 
US Drought Monitor (USDM; Svoboda et al., 2002), European Drought Observatory (EDO; Estrela and Vargas, 2012), and German Drought Monitor (GDM; Matthias et al., 2016). Some of the global systems, such as GIDMaPS can be applied for country scale assessment as well, and indices in these systems have also been applied for a long time, for example in China (Kogan et al., 2005; Zou et al., 2005; Yu et al., 2014; Zhang et al., 2016). Further, new drought indices also have been proposed for drought monitoring in China, including Drought Severity Index (DSI; Su et al., 2003), Modified Perpendicular Drought Index (MPDI; Ghulam et al., 2007), Optimized Meteorological Drought Index (OMDI; Hao et al., 2015), and Integrated Surface Drought Index (ISDI; Wu et al., 2015). Building on the need for more perspectives on drought, our broader goal is to develop a novel drought monitoring system based on a new drought monitoring framework and index.

Currently, most drought indices in drought systems have been modeled by univariate analysis, or multivariate (and bivariate) analysis (Mishra and Singh, 2010; AghaKouchak et al., 2015b).

Univariate analysis focuses on one drought-related environmental variable (McVicar and Jupp, 1998), such as the Standardized Precipitation Index (SPI; McKee et al., 1993), Vegetation Condition Index (VCI; McVicar and Jupp, 1998), Standardized Soil Moisture Index (SSI; AghaKouchak, 2014), and Standard Relative Humidity Index (SRHI; Farahmand et al., 2015). By design, a univariate index can capture anomalous changes that occur in one key environmental 
variable. However, to define a drought, especially agricultural drought, which is affected by uncertainties (i.e., disease, flood, and field management), univariate indices are insufficient to investigate associated evolutions and impacts (Charusombat and Niyogi, 2011; Hao and AghaKouchak, 2014).

Table 1 lists a summary of several typical multivariate analyses. In particular, bivariate analysis is a subset of multivariate analysis and typically combines data from land surface temperatures and vegetation conditions, such as the Vegetation Health Index (VHI; Kogan, 2002). Similar bivariate indices include the ratio of land surface temperature and Normalized Difference Vegetation Index (NDVI) (McVicar and Bierwirth, 2001) and Standardized Precipitation Evapotranspiration Index (SPEI; Vicente-Serrano et al., 2010). Studies such as (Mishra and Singh, 2011) have documented some drawbacks of bivariate analysis and their applicability.

A broader subset of multivariate analysis integrates more than two variables, for example the Microwave Integrated Drought Index (MIDI; Zhang and Jia, 2013), which is combined by precipitation, soil moisture, and land surface temperature. Other proposed multivariate indices include the Multi-sensors Drought Severity Index (MDSI; Chen et al., 2014), the Optimized Vegetation Drought Index (OVDI; Hao et al., 2015), and the Multivariate Drought Index (MDI; Rajsekhar et al., 2015a). In recent year, copula-based bivariate and multivariate drought modeling have also shown effectiveness in drought assessment (Kao and Govindaraju, 2010; Maity et al., 2013; Rajsekhar et al., 2015b), and also the Multivariate 
111 Standardized Drought Index (MSDI; Hao and AghaKouchak, 2013).

112 Reviewing the past studies, we postulate that, the goal of drought assessment

113 including impact consideration can be effectively met by integrating information

114 from multivariate analysis and multi-sensors. Inspired by this idea, this study

115 seeks to monitor agricultural drought based on its evolution process using a

116 multi-sensor collaboration approach and a multivariate analysis model. The

117 integration of drought evolution and crop phenology then can be quantified.

118 Therefore, it is needed to combine appropriate sensors/datasets to monitor

119 precipitation, soil moisture, and crop conditions in a systematic manner. Thus,

120 there are three main objectives of this study. (a) To design a collaborative

121 monitoring framework based on multi-sensor approach for the drought

122 evolution process, referred to as the Evolution Process-based Multi-sensor

123 Collaboration (EPMC) framework. (b) To propose a Process-based Accumulated

124 Drought Index (PADI) under the EPMC framework to assess drought impacts on

125 regional crops. (c) To compare PADI with multi-time scale SPI, the Palmer

126 Drought Severity Index (PDSI), and crop yield loss data in three different climate

127 regions. The study will thus form a new agricultural drought monitoring

128 capability building off remote sensing integrated multi-sensor approach. 
130 Summary of typical studies using multivariate analysis for agricultural drought monitoring/evaluation, including experiment region and year, data,

131 methodology, and key findings. Some of the readily accessible data/products were listed while its derived data was not included here. Unit of "Data length" is

132 year. "ESI = Evaporative Stress Index; VegDRI = Vegetation Drought Response Index; SDI = Synthesized Drought Index; PCA = Principal Component

133 Analysis; CLSMAS = China Land Surface Soil Moisture Assimilation System; OVDI = Optimized Vegetation Drought Index; RWC = Relative Water Content;

$134 \mathrm{CPC}=$ Climate Prediction Center; KECA $=$ Kernel Entropy Component Analysis; SDCI $=$ Scaled Drought Condition Index; NLCD $=$ National Land Cover

135 Database; ISDI = Integrated Surface Drought Index; CART = Classification And Regression Tree. The studies are listed alphabetically.

\begin{tabular}{|c|c|c|c|c|c|c|}
\hline \multirow{2}{*}{ No. } & \multirow{2}{*}{ Reference } & \multirow{2}{*}{ Region and Year } & \multirow{2}{*}{ Data } & Data & Model/Algorithm & \multirow{2}{*}{ Key findings } \\
\hline & & & & length & /Main steps & \\
\hline \multirow[t]{3}{*}{1} & Anderson & Brazil & MODIS LAI ( 1 km, 4 day); MODIS LST & 10 & ESI calculation ; Index anomalies & At the state scale, the ESI provided higher yield \\
\hline & al. & $(2003-2013)$ & (1 km, daily); MERRA; TRMM & & standardization; Yield correlation; Does & correlations for most crops and regions in \\
\hline & $(2016)$ & & precipitation $\left(0.25^{\circ}\right.$, daily $)$ & & not consider crop modeling & comparison with TRMM and LAI anomalies. \\
\hline 2 & Brown et & North-central, & SPI (bi-weekly); PDSI (bi-weekly); & 16 & Eight inputs processing; Empirically & VegDRI represents an objective, repeatable, and \\
\hline
\end{tabular}


al. (2013) U.S. (2002)

AVHRR NDVI (1 km); Start of season;

Land cover (30 m); AWC; Irrigated

Agriculture (1 km); Ecoregions

Du et al. Shandong, China MODIS NDVI (1 km, monthly); LST (1

(2010-2011)

km, 8 day); TRMM precipitation

$\left(0.25^{\circ}\right.$, monthly)

4 Hao et al. Southwest

of TRMM precipitation $\left(0.25^{\circ}\right.$, monthly); 5

China

MODIS LST (1 km, 16 day); AMSR-E

(2005-2009)

SM (25km); CLSMAS $\left(0.1^{\circ}\right) ;$ MODIS

NDVI (1 km, 16 day) derived model generation; VegDRI high resolution approach to drought monitoring

mapping; Consider crop modeling that can be implemented in a near real-time

fashion.

VCI, TCI and PCI derivation; SDI SDI is strongly correlated with SPI-3, variation of calculating by PCA; Does not consider crop yield and drought-affected crop areas.

crop modeling

Indices scaling; OVDI combination by

OVDI was best correlated to SPEI-3, and had a

empirical weights, PCA, and constrained similar trend with soil RWC in temporal scale.

optimization; Does not consider crop

modeling

SPI and SSI preparation; Copulas based MSDI describes the drought onset as early as SPI,

conjunction; Does not consider crop while it shows drought persistence similar to SSI.

modeling

MSDI shows a more severe drought condition 
6 Rajsekhar Texas,

U.S. NOAA precipitation $\left(1 / 8^{\circ}\right.$, monthly);

et

al. (1950-1957, $\quad$ Runoff $\left(1 / 8^{\circ}\right.$, monthly); Actual

(2015a） 2010-2011)

evapotranspiration

Rhee et al. Arizona and New MODIS LST ( $1 \mathrm{~km}, 8$ days); MODIS 10

Mexico, North NDVI (1 km, monthly), MODIS

Carolina and reflectance $(500 \mathrm{~m}, 8$ day); NLCD (30

South Carolina, m), TRMM precipitation $\left(0.25^{\circ}\right.$,

U.S. (2000-2009) monthly)

8 Wu et al. Mid-eastern

MOIDS NDVI (1 km, 16 days); MODIS

10

63 normal variates; MDI extraction based the

on KECA; Does not consider crop

modeling

Inputs scaling; SDCI calculation by

selected weights combination;

Regression analysis with crop yield; year-to-year changes and spatial distributions of

Does not consider crop modeling

SDCI over both arid and humid regions generally

agreed to the USDM

14 inputs processing (PDSI, SPI, NDVI, ISDI can be used not only to monitor the main

LST...); Integrated multisource data drought features, including precipitation

and termination of droughts.

DCI performed better than existing indices such

as NDVI and Vegetation Health Index; The
(2013,

China

LST (1 km, 8 day); Ecological zoning (1 
management distribution $(10 \mathrm{~km})$

$\operatorname{DEM}(1 \mathrm{~km})$
Evaluation of different integration also to indicate the Earth surface thermal and

models; Consider crop modeling water content properties by incorporating

temperature information. 


\section{Study Area and Data}

137

138

139

140

141

142

143

144

145

146

147

148

149

150

151

152

153

154

155

\subsection{Study area}

This study focuses on three typical grain production locales in China, including Hubei province (region A), Yunnan province (region B), and Hebei province (region C) shown in Fig. 1 and Table 2. These three regions were strategically chosen due to their importance for agriculture production, diversity in climate feature, and geographical diversity in the central, south, and north of China (Fig. 1). This area produced over 79 million tons in 2015, nearly one-sixth of China's total wheat production according to National Bureau of Statistics of the People's Republic of China (2015). These three regions also have diverse climate: including subtropical humid monsoon, tropical humid monsoon, and semi-arid temperature. The study area incorporates complex terrains, such as the Yunnan-Guizhou plateau, Jianghan plain, hilly areas, and North China plain. These drought prone areas were also often selected for drought analysis in China in prior studies (Zhou et al., 2012; Wu et al., 2013, 2015; Abbas et al., 2014; Yu et al., 2014; Liu X. et al., 2015; Ray et al., 2015). In the current study, three notable drought events that were recorded in recent years over these three regions were selected (see Table 2). Development and testing of the EPMC framework and PADI were conducted to collaborate multiple data sources over these three regions, and is expected to provide a robust assessment and good comparability. 


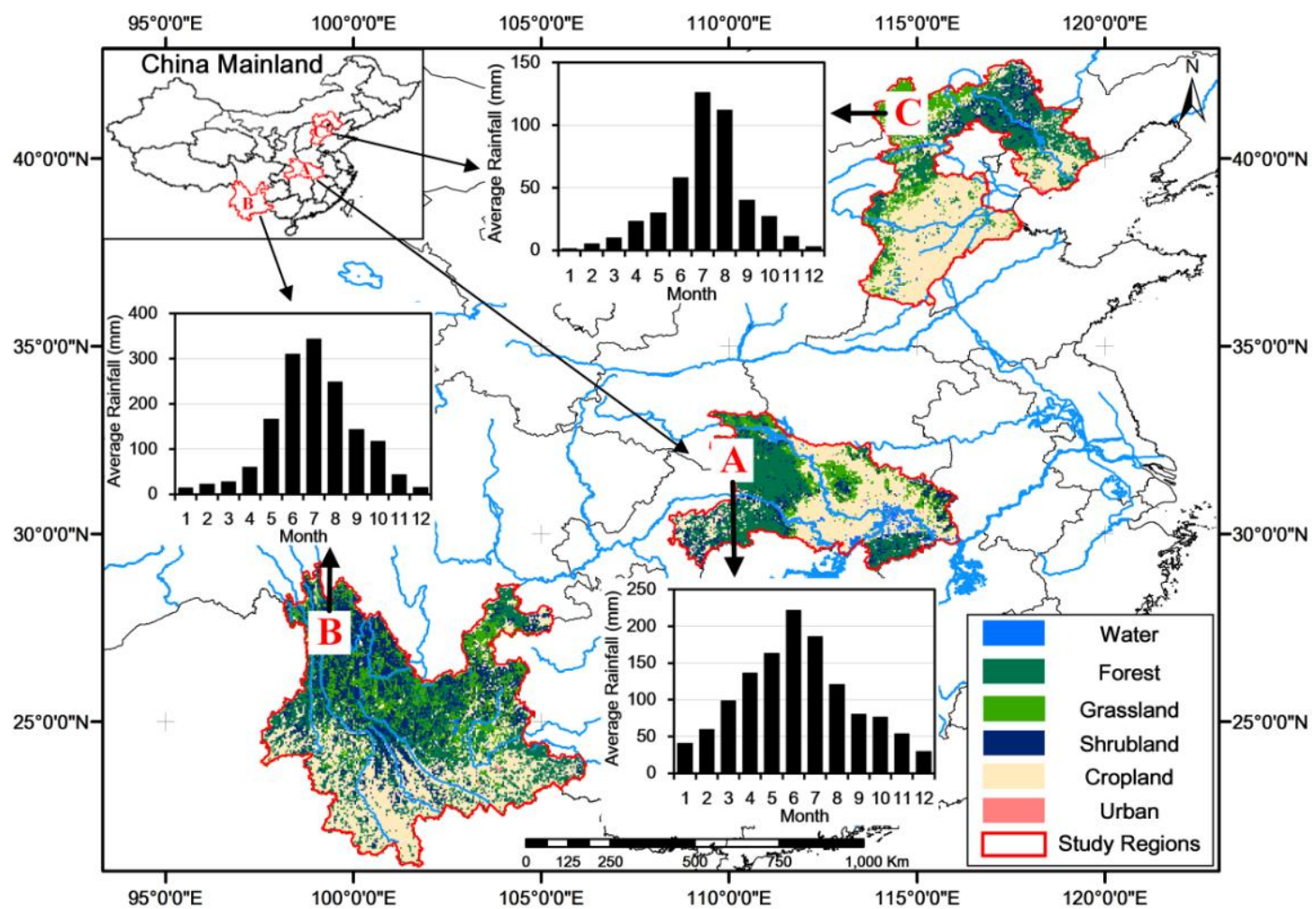

Figure 1. Study area includes (A) the subtropical humid monsoon region of Hubei province,

(B) the tropical humid monsoon region of Yunnan province, and (C) the semi-arid

temperature region of Hebei province. Their relative locations in mainland China, land cover, and average monthly precipitation are shown.

Table 2

Major climatic and socio-economic characteristics of the study area. The units for area covered, population, sunshine hours, annual precipitation, and annual average temperature are $\mathrm{km}^{2}$, million, hour, $\mathrm{mm}$, and ${ }^{\circ} \mathrm{C}$, respectively. The unit of agricultural gross domestic product (GDP) and agricultural loss are in billion USD.

\begin{tabular}{llll}
\hline Study Area & Region A & Region B & Region C \\
\hline Climate division & Subtropical humid monsoon & Tropical humid monsoon & Semi-arid temperature \\
Area Covered & 185,900 & 390,000 & 187,700
\end{tabular}




\begin{tabular}{llll} 
Population & 57.79 & 45.96 & 72.88 \\
Sunshine hours & 1865 & 2200 & 2303 \\
Annual precipitation & $800-1600$ & $1100-1600$ & $400-800$ \\
Annual temperature & $15-17$ & $5-24$ & $4-13$ \\
2014 agricultural GDP & 3176.89 & 1991.17 & 3447.5 \\
Selected drought year & 2011 & & 2010 \\
Agricultural loss & 1.18 & 2010 & 3.00 \\
\hline
\end{tabular}

2.2 Data

To achieve drought evolution process monitoring, long-term precipitation, root zone soil moisture, and vegetation data were integrated. Additionally, SPI, PDSI, and crop yield loss data were also obtained/calculated for validation purpose. The following is a brief description of these datasets.

The 30 years of precipitation data back to 1981 were obtained from the Global Precipitation Climatology Centre (GPCC) full data reanalysis version 7

173 (Schneider et al., 2015). The GPCC full data reanalysis monthly product is 174 comprised of monthly totals on a regular grid with a $0.5^{\circ}$ spatial grid spacing. Precipitation anomalies at the gauge stations are interpolated and superimposed on the GPCC Climatology V2015 in the corresponding resolution (Becker et al., 2013). Based on this dataset, SPI was calculated at 3-, 6-, 9-, and 12-month time 178 scales using the Standardized Drought Analysis Toolbox (SDAT) (Farahmand and AghaKouchak, 2015). There are two approaches to validate the proposed PADI using SPI: spatiotemporal drought comparison and correlation analysis. The 
181

182

prior approach was to investigate spatiotemporal similarities and differences in drought distribution and severity provided by them, respectively. The latter was to evaluate the time scale feature of PADI in assessing drought by calculating correlation coefficients with multi-scale SPIs.

For agricultural drought modeling, root zone soil moisture is important and relatively stable compared to the surface soil moisture, because the latter is sensitive to other environmental variables (e.g., temperature) that drive atmospheric evaporative demand. In this study, the Global Land Data Assimilation System version 2 (GLDAS-2.0) Noah Land Surface Model L4 product with $0.25^{\circ}$ grid spacing from 1980 was used (Rodell et al., 2004). This monthly product is one of the few root zone soil moisture products with more than 30 years record in China, and it also has higher spatial resolution than MERRA-Land data $\left(0.25^{\circ}\right.$ vs. $\left.0.5^{\circ}\right)$. It was generated through temporal averaging of the reprocessed 3-hourly data, and encompasses a series of land surface parameters including root zone soil moisture simulated from Noah Model 3.3 (Rodell et al., 2004). This satellite-model merged data was validated by Chen et al., (2013) and Bi et al., (2016), and was also used to capture soil moisture anomalies and variability (Dorigo et al., 2012; Spennemann et al., 2015; Yuan et al., 2015).

To collect 30 years of crop conditions, the Advanced Very High Resolution Radiometer (AVHRR) Vegetation Health Product (VHP) was obtained from the National Oceanic and Atmospheric Administration (NOAA) Center for Satellite Applications and Research. AVHRR-VHP is a reprocessed vegetation health 
dataset that uses multi-indices (NDVI, VCI, and TCI) (Kogan 2002). Compared with other widely used NDVI3g (third generation NDVI from AVHRR by Global Inventory Monitoring and Modeling System in National Aeronautics and Space Administration), NOAA NDVI dataset has both fine spatial-temporal resolutions. A validation experiment (summarized in the Appendix) also showed the reliability of NOAA NDVI dataset to derive VCI in this study. For this study, weekly VCI $4 \mathrm{~km}$ product from 1981 was selected. There are at least four mappings of vegetation conditions along with monthly precipitation and soil moisture measurements. To ensure that these four vegetation mappings are equispaced for each month, products that are close to day $1,8,15$, and 22 were selected.

The Penman-Monteith (PM) model based PDSI data was obtained from National Center for Atmospheric Research (NCAR) (Dai et al., 2004; Dai 2011 and 2013). PDSI uses temperature and precipitation data in a potential evapotranspiration (PET) model to estimate relative dryness as a drought index (Palmer 1965; Rhee et al., 2010; Zargar et al., 2011). PDSI is effective in determining long-term drought, especially over low and middle latitudes (Dai et al., 2004 and 2011), and it also takes precedent conditions into account. One notable weakness of PDSI is that the original used simplified PET model (Thornthwaite equation), which only considers precipitation and temperature. Recently, it was reported that using more sophisticated PET model or direct PET observations aided more realistic drought assessment using PDSI (Hobbins et al., 2008; Sheffield et al., 2012; Yan et al., 2016). PDSI is not comparable across 
regions as SPI, and this was alleviated by using self-calibrating PDSI (Sc_PDSI; Wells et al., 2004). Additionally, the PDSI also introduces error in its treatment of all precipitation being immediately available rain (i.e., no delayed runoff from melting snow), and its lack of impact of vegetation interception or frozen soils on evaporation. In this study, PDSI was used to compare with the proposed PADI in terms of the spatial-temporal features and percentages of different drought-affected areas. Based on this analysis, different drought modeling approaches used by PDSI and PADI were discussed further.

Yield data of each prefecture in the study area from 2000 to 2011 was combined by reviewing agriculture information from the respective crop statistics yearbook (almanac) for Yunnan, Hubei, and Hebei regions. These statistical yearbook were obtained from the China National Knowledge Infrastructure (http://www.cnki.net/) (Wang et al., 2014). Based on these yearly yield data, yield loss data can be obtained to represent impact in drought years. In this study, yield loss is defined as the reduction of crop yield weight per unit relative to 10 years of statistics. Crop yield time series were de-trended by using the best-fit least squares regression method to remove crop yield trends due to improvements in seed, varying fertilizer, and planting date (Niyogi et al., 2015). To validate the performance of PADI, the yield loss data in prefectures was correlated with the corresponding mean PADI values. Spearman rank correlation coefficients between yield loss and precipitation deficit, soil moisture deficit, and NDVI anomaly were also calculated for comparison. It is aimed to help 
understand the improvements of PADI model by integrating multi-sensor

248 information in drought modeling.

249

250

251

252

253

254

255

256

257

258

259

260

261

262

263

264

265

266

\section{Methodology}

\subsection{Evolution Process-based Multi-sensor Collaboration (EPMC) framework}

Drought is generally a slow-onset natural hazard although "flash drought" sometimes occurs. This study is concentrated on the more commonly and long-term lingering agricultural droughts, which last for a few months, even years. A monitoring framework is introduced that is based on multi-sensor approach to identify different phases of agricultural drought evolution. This framework is referred to as the Evolution Process-based Multi-sensor Collaboration (EPMC). EPMC was extended from a recognized conceptual model (National Weather Service, 2008; National Drought Mitigation Center; Li et al., 2013), which only describes the drought evolution in a qualitative manner. The EPMC is designed to provide input to the proposed PADI as described in the following section.

In EPMC, we categorized agricultural drought evolution into four phases (Fig. 2): (i) Latency, (ii) Onset, (iii) Development, and (iv) Recovery. Each phase corresponds to different qualitative changes through the drought life cycle. The EPMC focuses on one critical environmental variable (i.e., precipitation, root zone soil moisture, and vegetation) in each drought phase. 


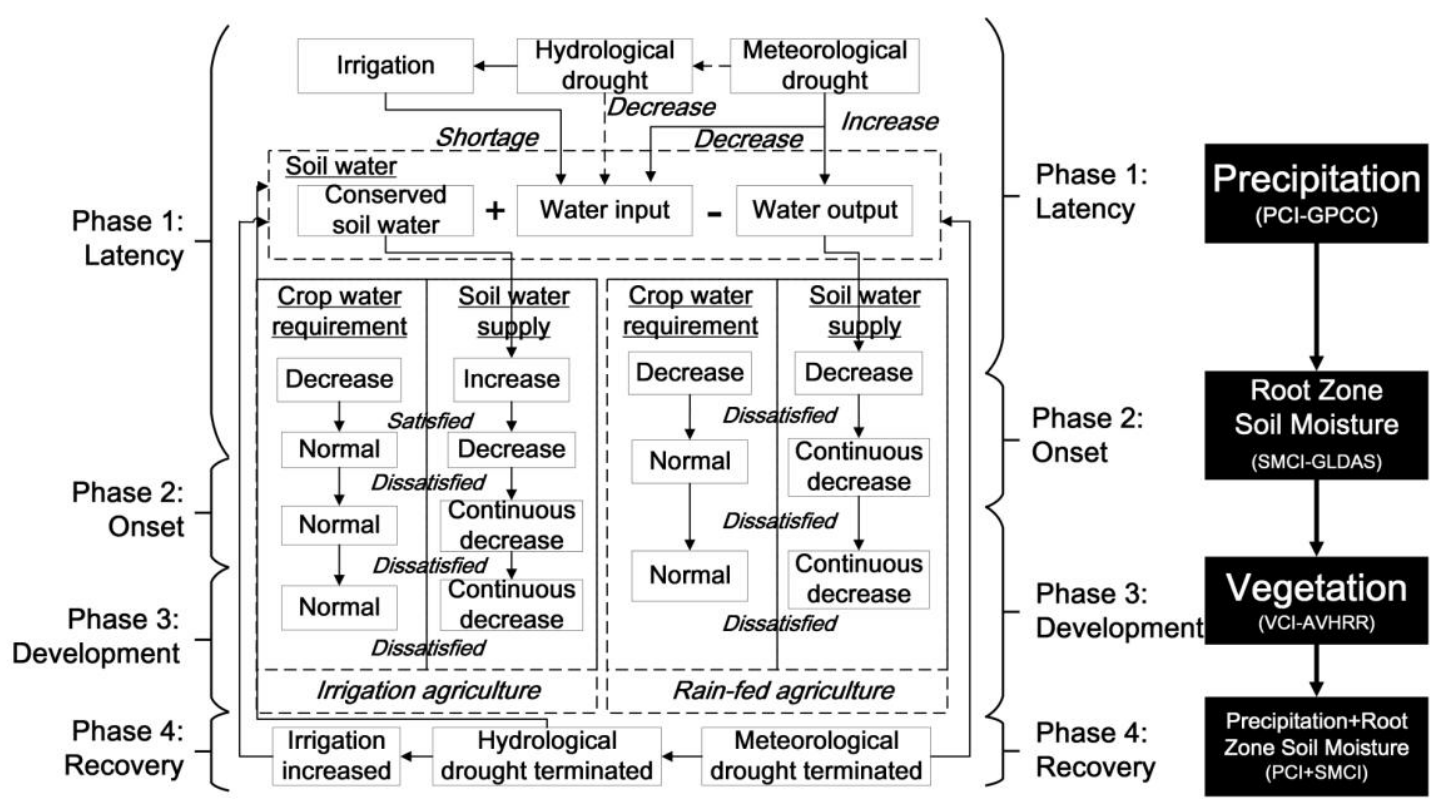

Figure 2. The flowchart of EPMC and the basic evolution process of agricultural drought that

includes latency, onset, development, and recovery phases. Regardless of whether irrigated

precipitation to available soil moisture and to vegetation stress. The EPMC combines GPCC,

272 GLDAS, and AVHRR datasets/sensors to identify these phases (shown on the right side). PCI

273 (Precipitation Condition Index), SMCI (Soil Moisture Condition Index), and VCI (Vegetation

274 Condition Index) are used to quantify anomalies of precipitation, soil moisture, and

275 vegetation separately. It is emphasized that as long as the variable orders and indices remain

276 unchanged, the remote sensors/dataset used in EPMC could be replaced by similar ones.

In most cases, an agricultural drought begins as a meteorological drought.

higher air temperatures and increased potential evapotranspiration (Mueller and

Seneviratne, 2012). When the water balance starts to get negative, it indicates 
not formed yet, so the vegetation has not actually been visibly impacted. In the U.S. drought monitor, this stage is similar to the "D0 or abnormally dry" (Svoboda et al., 2002). In this phase, an anomaly in precipitation is quantified by the Precipitation Condition Index (PCI) based on the GPCC data. The PCI was defined below to capture the precipitation deficit:

$$
\mathrm{PCI}=\frac{\mathrm{P}-\mathrm{P}_{\min }}{\mathrm{P}_{\text {max }}-\mathrm{P}_{\min }}
$$

Where $\mathrm{P}, \mathrm{P}_{\max }$, and $\mathrm{P}_{\min }$ are the pixel values of precipitation, and its maximum and minimum value, respectively. The maximum and minimum (i.e. range) were obtained from precipitation data from the same month during the last 30 years. PCI changes from zero to one corresponding to changes in precipitation conditions from extremely unfavorable to near flooding. That is to say in the case of a meteorological drought, which has low precipitation, the PCI is close or equal to zero, while during flooding conditions, the $\mathrm{PCI}$ is close to one. Its capability in quantifying precipitation deficit has already been demonstrated by studies from Du et al., (2013), Zhang and Jia (2013), and Hao et al., (2015). Additional comparison between PCI and SPI is shown in the Appendix. Before calculation, it is necessary to get rid of outliers, and we also tested different threshold values and concluded that a value of 0.5 was adequate to represent an anomalous precipitation event.

In the latency phase, the deficit of precipitation results in a subsequent root zone soil moisture deficit. In this condition, crop water requirements initially decrease to adapt to this water-limited environment, and lead to a drop in actual 
evapotranspiration. During this stage, access to irrigation can provide soil water to some extent, while rain-fed agriculture will continue seeing a nearly continuous soil water decline. Regardless of which agricultural type is present, crop self-regulation does not continue in perpetuity and irrigation water deficit also starts becomes limiting. Therefore, the effects of root zone soil water deficit will be felt by the crop eventually. We refer to this phase as the "Onset" (Fig. 2). To quantify it, the soil moisture condition index (SMCI) was calculated as:

$$
\mathrm{SMCI}=\frac{\mathrm{SM}_{-} \mathrm{SM}_{\text {min }}}{\mathrm{SM}_{\text {max }}-\mathrm{SM}_{\text {min }}}
$$

Where $\mathrm{SM}, \mathrm{SM}_{\max }$, and $\mathrm{SM}_{\min }$ are the pixel values of root zone soil moisture, its maximum and minimum, respectively, during the same month in the past 30 years. If an anomalous SMCI (e.g., less than 0.5) occurs follows an anomalous occurrence of PCI, this series of events indicates that the meteorological drought may very likely develop into an agricultural drought.

During soil water-stressed conditions, vegetation typically responds by decreasing actual evapotranspiration. Note that the vegetation can show response to moisture deficits within a day via stomatal closure (Niyogi and Raman, 1997). While from a longer-term perspective, there could be a response in terms of reduced green leaf area (Zhao and Running, 2010). It is important to highlight that micro-changes may not be fully captured by satellite remote sensing, although the sun-induced fluorescence monitoring showed some promising results (Guanter et al., 2014; Yang et al., 2015). Therefore, the third "Development" phase is defined based on the macro-changes of green leaf 
fraction, which is more commonly detectable by satellite sensors. Such a change was measured quantitatively by the VCI, which is defined as:

$$
\mathrm{VCI}=\frac{\mathrm{NDVI}^{-N D V I} \mathrm{I}_{\text {in }}}{\mathrm{NDVI}_{\max }-\mathrm{NDVI}_{\text {min }}}
$$

Where NDVI, $\mathrm{NDVI}_{\max }$, and $\mathrm{NDVI}_{\min }$ are the pixel values of NDVI. The maximum and minimum are considered during the same week in the past 30 years. Note that since the vegetation response is usually more rapid than soil, both in terms of environmental changes as well as our ability to detect, the values are at weekly scale. Also the threshold value that worked most efficiently was set as 0.6 (and not 0.5 as for other indices). If VCI is below 0.6 , the vegetation is considered to have been distinctly impacted by the drought. After this phase, if precipitation occurs then the drought condition can start to improve. How much rain is needed to eliminate the drought is an important question, but it is beyond the scope of this paper; however, the vegetation would likely sense the recharge of soil moisture. Therefore, the precipitation and soil moisture values are combined to assess this change of phase. We require that both PCI and SMCI should return to normal indicating that sufficient rainfall has provided enough soil moisture availability in the root zone. Even for this threshold, we note that the vegetation may not fully recover due to the irreversible damage by drought. Nonetheless, we refer to this phase as the final "Recovery" phase The actual evolution of agricultural drought is often much more complex than the schematic outlined processes in Fig. 2. For example, VCI may vary due to crop planting, harvest, disease, and other such management decisions or stresses. The 
root zone soil moisture may be recharged by increased spring snowmelt water flow and be impacted by agricultural operations (Liu Y. et al., 2015). Therefore, the EPMC should be regarded as a simplified potential model which integrates three core variables for assessing an agricultural drought. By doing so, EPMC simultaneously quantifies the evolution of drought by multi-sensor datasets. Based on these numerical inputs, and index referred to PADI is proposed.

\subsection{Process-based Accumulated Drought Index (PADI)}

Crop physiology has demonstrated that the uppermost leaves (i.e., the crown leaves) are important sources of carbohydrate production for cereal crops (Miller, 1992). Further, crop yields have a positive relationship with soil moisture and vegetation anomalies during certain growth stages (Li et al., 2013). Considering this, it is possible to assess agricultural drought severity by integrating remotely sensed soil and vegetation indices in conjunction with crop growth characteristics. Fig. 3 demonstrates this idea, with evolution of drought and crops, respectively. Just as droughts evolve, crops also have different growth phenological phases, and during each phase, they have different sensitivities for water-deficiency. The PADI calculation is made until the end of drought or crop growth. 


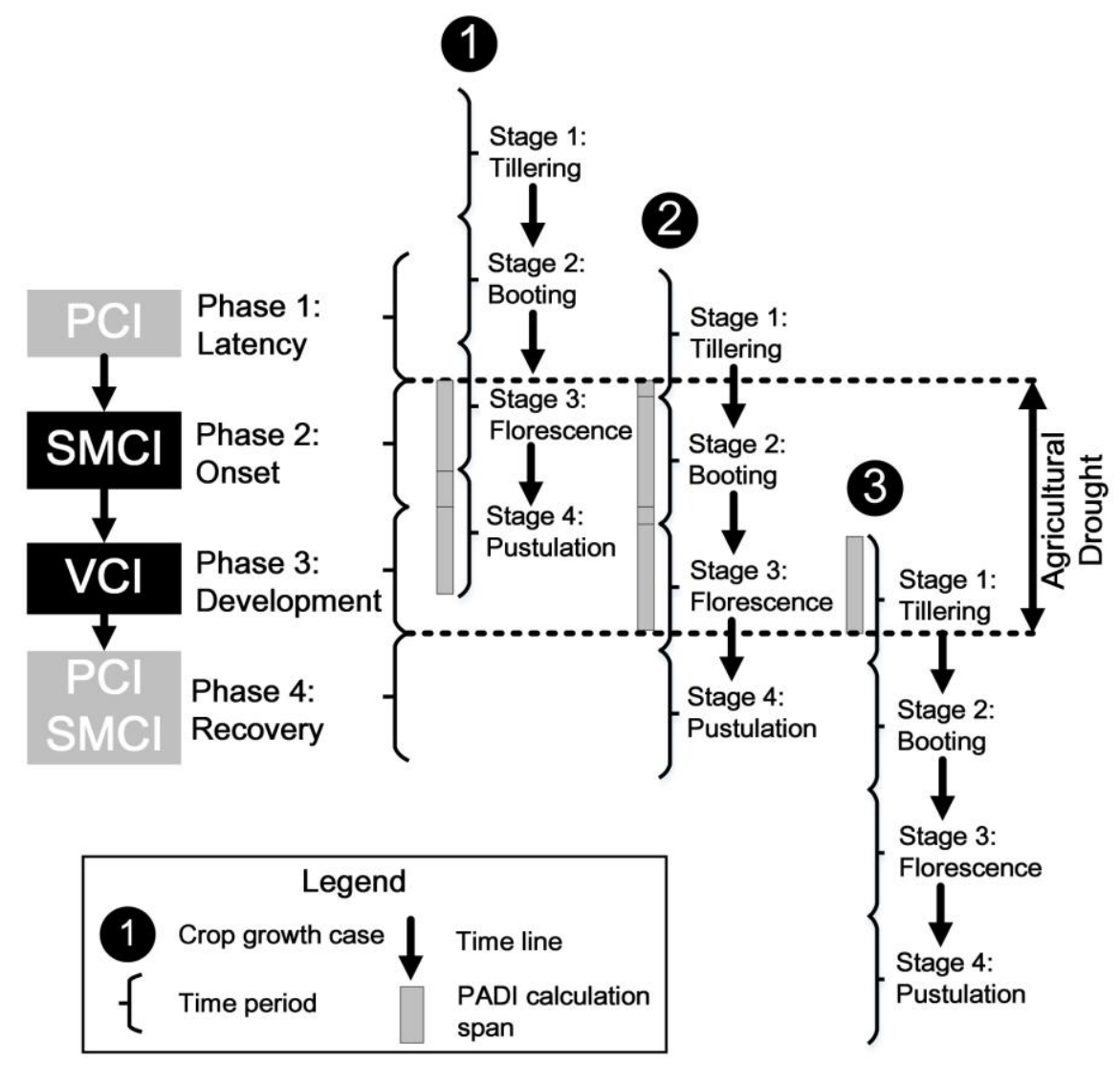

Figure 3. The schematic diagram of PADI. On the left, EPMC divides the agricultural drought

369 into four evolution phases using PCI, SMCI, and VCI indices. On the right, there are three

typical crop growth phases to show their different interactions with the drought. For every

crop growth case, different growth stages were divided to represent different soil water

sensitivity. In this paper, we consider the widely cultivated wheat in the study area as an example, so there are tillering, booting, florescence, and pustulation stages. The grey bars indicate different calculation spans of PADI, which is the common period of the drought onset phase and the development phase with crop growth. The divisions of the PADI grey bar represent the changes of parameters when calculated, since the drought phase or water-deficit sensitivity is changed at that time. 
soil moisture and vegetation datasets. Mathematically, PADI is formulated as:

$$
\mathrm{PADI}_{t}=\mathrm{PADI}_{t-1}+\frac{\sum_{i=1}^{n}\left[\left(T \cap s_{i} \cap p_{2}\right) * \lambda_{i} *\left(1-S M C I_{t}\right)+\left(T \cap s_{i} \cap p_{3}\right) *\left(1-V C I_{t}\right)\right]}{\mathrm{PADI}_{\text {max }}}
$$

Where PADI $t_{\mathrm{t}}$ is the indxe value at time $t$, and T is the duration of this assessment period. Here T is 7 days, so PADI will be refreshed weekly. $s_{i}$ represents different crop growth stages in the study area, and $n$ is the total number of growth stages. The $\mathrm{p}_{2}$ and $\mathrm{p}_{3}$ are the durations of the onset phase and the development phase, respectively. $T \cap \mathrm{s}_{i} \cap \mathrm{p}_{2}$ represents the duration of the intersection between the current calculation week, growth stage $i$, and the onset phase, which is similar to $\mathrm{T} \cap \mathrm{s}_{i} \cap \mathrm{p}_{3} . \lambda_{\mathrm{i}}$ is the water-deficit sensitivity coefficient in the growth stage $\mathrm{i}$, which describes the degree of soil water stress impacts on the crops. $S M C I_{t}$ and $\mathrm{VCI}_{\mathrm{t}}$ are the SMCI and VCI values during the period of $T \cap \mathrm{s}_{i} \cap \mathrm{p}_{2}$ and $\mathrm{T} \cap \mathrm{s}_{i} \cap \mathrm{p}_{3}$, respectively. Using these two univariate drought indices (SMCI and VCI) in PADI ensures anomalies in root zone soil moisture and vegetation can be directly represented. By adding the previous PADI value (PADIt-1), a higher PADI indicates increased accumulated impacts over the crop areas. The high severity agricultural drought occurs when crop growth is affected by extreme environmental conditions. In this case, PADI extends to the maximum value as, $\mathrm{PADI}_{\text {max }}=\sum_{i=1}^{n}\left[\left(s_{i} \cap p_{2}\right) * 1+\left(s_{i} \cap p_{3}\right) * 1\right]$, which is the denominator in equation (4). In calculating PADI, for the weeks corresponding to the onset phase of drought, only the SMCI data at $0.25^{\circ}$ resolution was used. If this time period coincides with the development phase of drought only, VCI data at $4 \mathrm{~km}$ alone was used. If 

scale to be integrated with VCI. To classify different drought severity according to PADI, an equi-partition schema was proposed and is shown in Table 3.

\section{Table 3}

Agricultural drought classification based on PADI. The range of PADI is from 0 to 1 , and the severity of drought was classified into five levels, corresponding to the USDM classifier.

\begin{tabular}{llllll}
\hline PADI value & $(0,0.20]$ & {$[0.21,0.40]$} & {$[0.41,0.60]$} & {$[0.61,0.80]$} & {$[0.81,1.00]$} \\
\hline Classifications & Abnormally dry & Moderate & Severe & Extreme & Exceptional \\
USDM Classifier & D0 & D1 & D2 & D3 & D4 \\
\hline
\end{tabular}
spatiotemporal drought evolution, as well as the crop phenology. We postulate that the quality of one growth stage influences the next growth stage. Therefore,

410 PADI is not a drought "snapshot" and is an accumulative index; similar to the idea

411 of growing degree days, which is an accumulation of heat.

413 If one study area is dominated by wheat, PADI can be used to quantify the impact

414 of drought on wheat, as long as the appropriate wheat parameters are introduced.

415 If corn is the main crop, PADI can also evaluate drought severity for corn using 416 the same formula (and is being studied in a following up assessment over the U.S.

417 Corn Belt). In this study, considering wheat, there are four main stages of growth:

418 the tillering, booting, florescence, and pustulation stage (composited from United

419 States Department of Agriculture, 2009). These growth stages of wheat, 
420 including their sensitivity coefficients in the study area are shown in Table 4.

421 These crop parameters can be derived from local farming conventions and 422 previous research (Wang et al., 2004).

423 Table 4

424 The four main growth stages of wheat in regions A, B, and C. The start and end time of these 425 stages for the study region are given along with the water sensitivity. Coe is the abbreviation 426 for water stress coefficient (Wang et al., 2004).

\begin{tabular}{|c|c|c|c|c|c|c|c|c|c|}
\hline \multirow{2}{*}{ Stages } & \multicolumn{3}{|c|}{ Wheat in region $\mathrm{A}$} & \multicolumn{3}{|c|}{ Wheat in region $B$} & \multicolumn{3}{|c|}{ Wheat in region $\mathrm{C}$} \\
\hline & Start & End & Coe. & Start & End & Coe. & Start & End & Coe. \\
\hline Tillering & Oct. 22 & Jan. 6 & 0.25 & Nov. 20 & Jan. 14 & 0.21 & Sep. 15 & Dec. 14 & 0.12 \\
\hline Booting & Jan. 7 & Apr. 9 & 0.30 & Jan. 15 & Feb. 28 & 0.30 & Dec. 15 & Apr. 30 & 0.31 \\
\hline Florescence & Apr. 10 & Apr. 19 & 0.33 & Mar. 1 & Mar. 30 & 0.32 & May 1 & May 30 & 0.31 \\
\hline Pustulation & Apr. 20 & May 15 & 0.12 & Apr. 1 & May. 10 & 0.17 & Jun. 1 & Jun. 20 & 0.26 \\
\hline
\end{tabular}

4. Results

\subsection{Agricultural drought evolution process using EPMC}

In this section, the results of EPMC are shown via a temporal evolution of

431 deviations are given. For brevity, only wheat growth relevant periods are shown here. Four drought evolution phases are delineated in different colors in the timeline and the inflections were marked as red squares representing the

434 occurrences of different phases. More details of EPMC results can be found in the Appendix section. Fig. 4 shows the 2011 drought devolution in the study region A 
growth stage in this area.

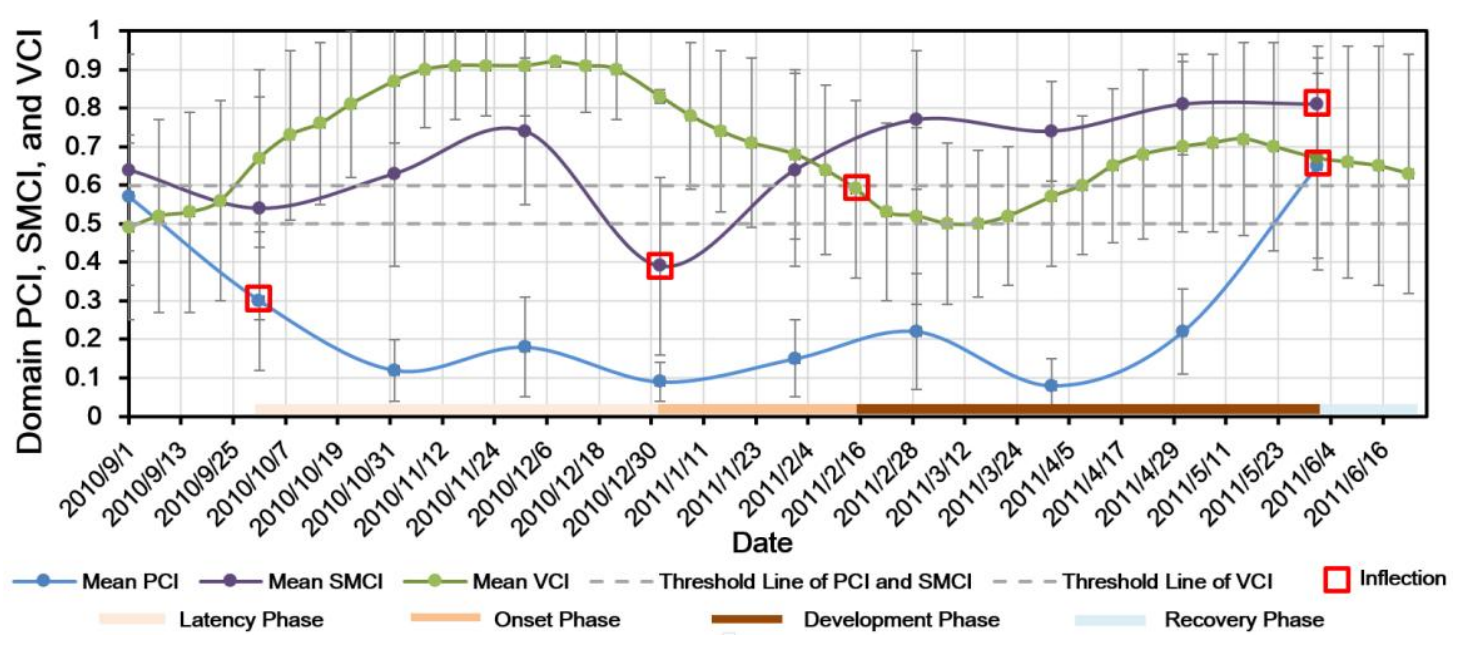

Figure 4. Mean and standard deviations of PCI, SMCI, and VCI under the EPMC framework in

region A. This plot is organized on a timeline from September 2010 to June 2011. PCI and

SMCI were obtained monthly, while VCI was updated weekly. The inflection denotes a new area was slightly more (mean PCI was 0.57 ), as compared to the 30 year average.

Root zone soil moisture was also higher than average (mean SMCI was 0.64 ). The VCI average was 0.49 , indicating a slightly-stressed vegetation state. Wheat had not been planted yet at this time. In October, a lower PCI (mean of 0.30) indicated a notable decrease of precipitation during this month, thus resulting in the decrease of soil moisture. At this time, EPMC reported the first phase (Latency) of agricultural drought start, while the soil moisture and vegetation were still 

454 for wheat (VCI was 0.91) which shows that the resilience of natural and 455 irrigation systems faced with a rainfall deficit. In January, the average SMCI 456 decreased to 0.39 , indicating the second phase (Onset) of drought. In January 457 458

temporary root zone soil moisture (SMCI was 0.74 ) could meet the water need and February, wheat was growing in water stress conditions. VCI then dropped from 0.83 to 0.59 by mid-February indicating the third (Development) phase at this point of time. In this phase, precipitation was still in short supply, especially in April (PCI ranged from 0.00 to 0.27 ). However, root zone soil moisture inversely developed, from 0.64 to 0.77 , then to 0.74 and 0.81 . This may be the result of increasing ground flow due to melting snow recharge as this area belongs to the Yangtze basin (shown in Fig. 1; Liu et al., 2009). Wheat was harvested by mid-May. In June, precipitation and soil moisture indices increased to 0.65 and 0.81 , respectively. Therefore, the last phase indicating the recovery of this drought event started in June. Overall, this agricultural drought event covered the booting, florescence, and pustulation stages of wheat growth from January 12011 to May 152011.

In region B with a tropical humid monsoon climate, drought in 2010 has a lengthy insidious and evolution feature as shown in Fig. 5. Long periods of low precipitation existed in this area from December 2008 according to PCI, indicating a 14-month latency phase. The root zone moisture values however indicated relatively normal conditions during this period, which could be due to inflow from developed river system and the high water hold capacity of soil. The 
paucity of rain led to a PCI value below 0.1 from October to February 2010. At this time, long-term low water input from rainfall finally resulted in the reduction in the root zone soil moisture (mean SMCI was 0.38 ). This is the onset phase. The mean SMCI continued its decline reaching a value of 0.24 . Correspondingly, VCI also decreased because of the water stress as well as the wheat booting stage. After March 8, mean VCI was 0.54. The regional VCI stayed below 0.6 for an extended period indicating a long development phase over this area. After the wheat harvest in May, the drought persisted. There were some precipitation events over the region and the rainfall amounts were below average, though the rains helped the soil moisture value to return to normal. Thus, this severe drought mainly covered the booting, florescence, and pustulation stages across the region, which was in a notable contrast to the tillering stage (November 20 -January 14).

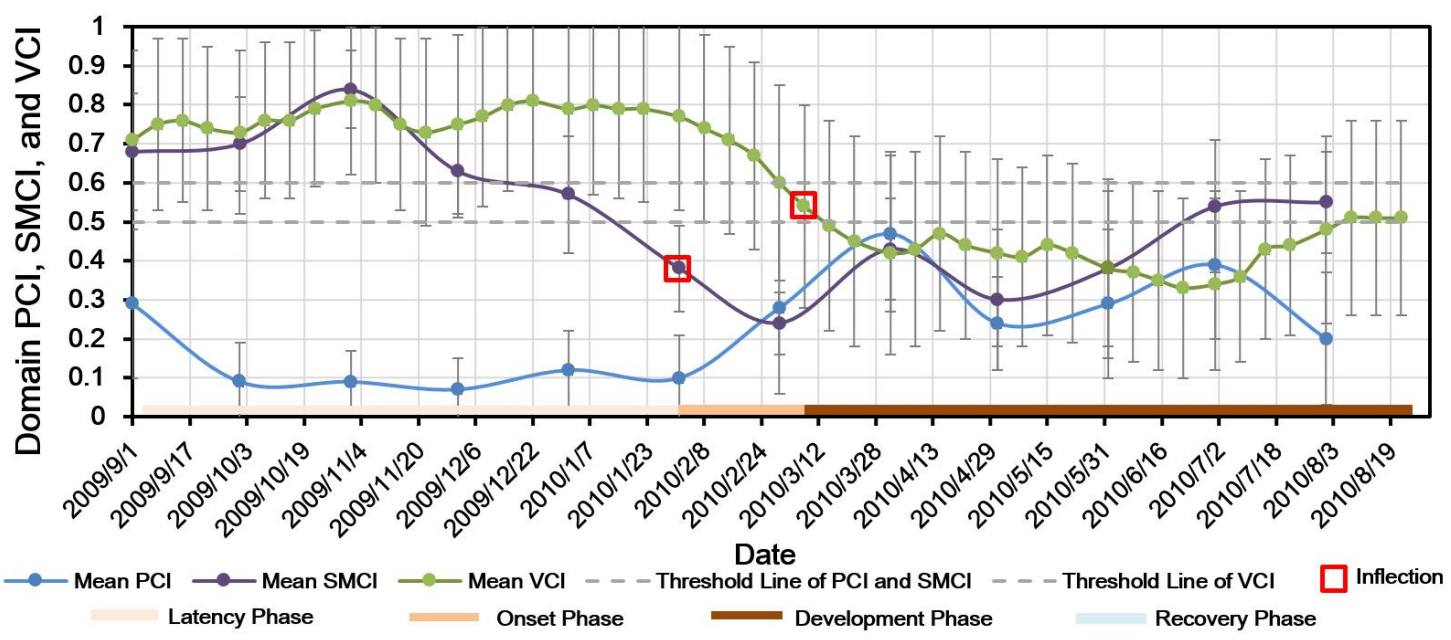

Figure 5. Same as Fig. 4 except for region B. This plot is organized on a timeline from September 2009 to August 2010.

Over study region $C$, the drought existed even longer than region $B$, as shown 
492

493

494

495

496

497

498

499

500

501

502

503

504

505

506

507

508

in Fig. 6. Reviewing the period corresponding to the wheat growth in 2010, the precipitation anomaly in this area appeared to have started in April 2006 (PCI was 0.26 ), with the drought beginning in June 2006 (SMCI was 0.45) according to EPMC. Therefore, when wheat was planted around mid-September, 2009, there was a near immediate influence of the drought. In this month, PCI was 0.47 and SMCI was 0.37. In December, precipitation index decreased to the minimum observed during the last 30 years (PCI ranged from 0.00 to 0.14 with mean value of 0.06). Wheat was affected by this water shortage, as evident from the values of VCI dipped below 0.4 from December to April, particularly during the first week of March (VCI was 0.31). In May, PCI increased to 0.50 and the SMCI and VCI showed corresponding increase as well. During the wheat harvest in June, crop conditions were relatively improved (VCI was around 0.5). Still this drought event continued to impact the next wheat planting until November 2011 according to EPMC. Thus, during 2010, wheat in this region was impacted by drought during all growth stages.

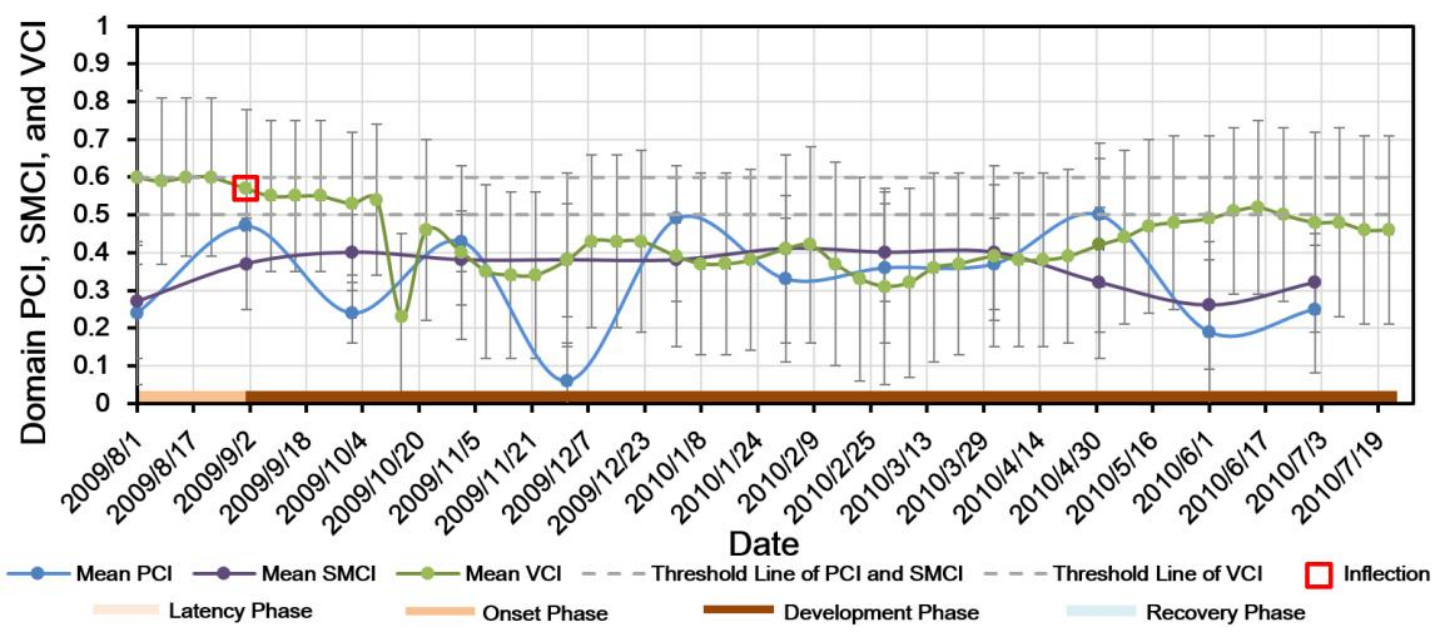

Figure 6. Same as Fig. 4 except for region C, and corresponding to a timeline of August 2009 
to July 2010 .

Based on the above EPMC results, clear impacts on the agricultural

511 production cycle could be observed via drought evolutions. For example, in

512 region $\mathrm{A}$, precipitation shortages starting in October led to the root zone soil

513 moisture anomaly in January, which then resulted in vegetation leaf stress from

514 February onwards. Similar features were noted for the other two study regions,

515 demonstrating the evolution of the phases of agricultural drought was effectively

516 captured by EPMC. Such spatiotemporal information of drought evolution was

517 input in the PADI model and detailed in the following section.

$518 \quad 4.2$ Agricultural drought assessment using PADI

519 Weekly PADIs were calculated for the three study regions to show

520 accumulated drought impacts during the wheat growing season. The drought

521 severity assessed by PADI in region A is shown in Fig. 7. 

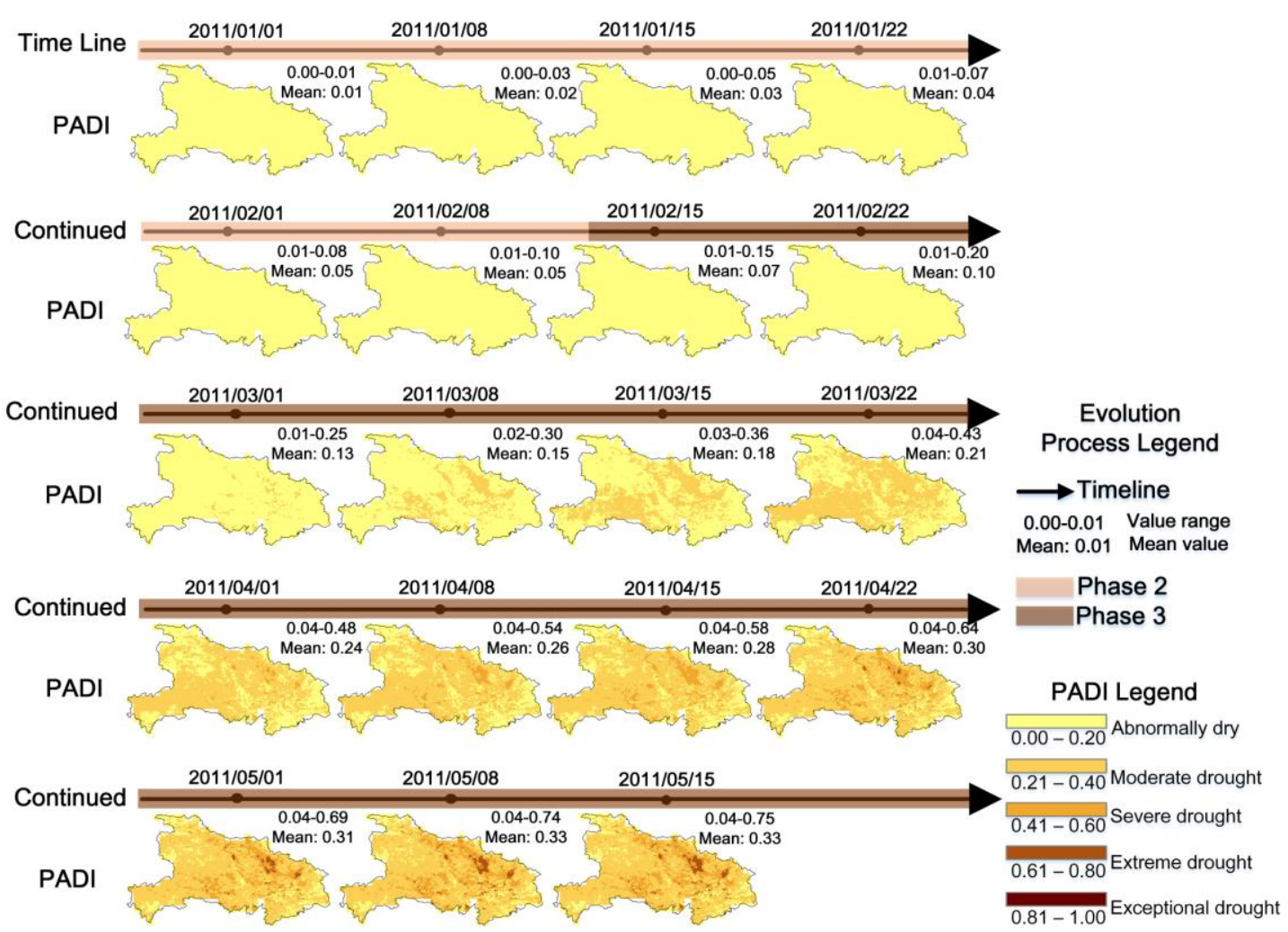

523 Figure 7. Agricultural drought severity mapping using PADI for region A. This result is shown

524 by a timeline from the start to the end of agricultural drought, which is from January 2011 to

525 May 2011. The onset and development phases are also marked in two colors above the

526 timeline. PADI maps were updated weekly with their ranges, means, and classifications.

PADI is calculated from the onset phase of the agricultural drought after

528 wheat planting and ranged from 0 to 0.01 on January 1,2011 . The whole area

529 was abnormally dry. With the development of drought, PADI increased to indicate

530 more as well as spatially-different drought impacts on wheat within this region.

531 On March 1, the regional mean PADI was 0.13, but in some central areas, PADI

532 increased above 0.20 , indicating that wheat in these areas were under a

533 moderate drought. Analysis corresponding to March 22 indicated moderate

534 drought conditions prevailed the entire region. Subsequently, severe drought 
emerged in the central northern areas. On May 1, the average PADI value increased to 0.31 , and extreme drought became apparent in the central north at that time. By the time wheat was harvested around mid-May, the majority of the region experienced moderate drought while the central areas experienced severe to extreme droughts.

Fig. 8 shows the drought severity in region B through the wheat growing season. Early February 2010, the mean PADI was around 0.01, indicating that there was relatively little drought impact in the beginning. These abnormally dry conditions continued until mid-March. In the south and east areas, moderate drought emerged. One week later, mean PADI increased to 0.21 , indicating that the drought progressed into a moderate drought affecting the whole region. From April 1 to 22, severe drought was present especially in the eastern areas and continued to develop into extreme drought in some areas into late April. During the harvest period, mean PADI in this region was 0.43-0.45. From the final mean value of PADI, it can be concluded that the 2010 drought in region B was more serious than the 2011 drought in region A. 


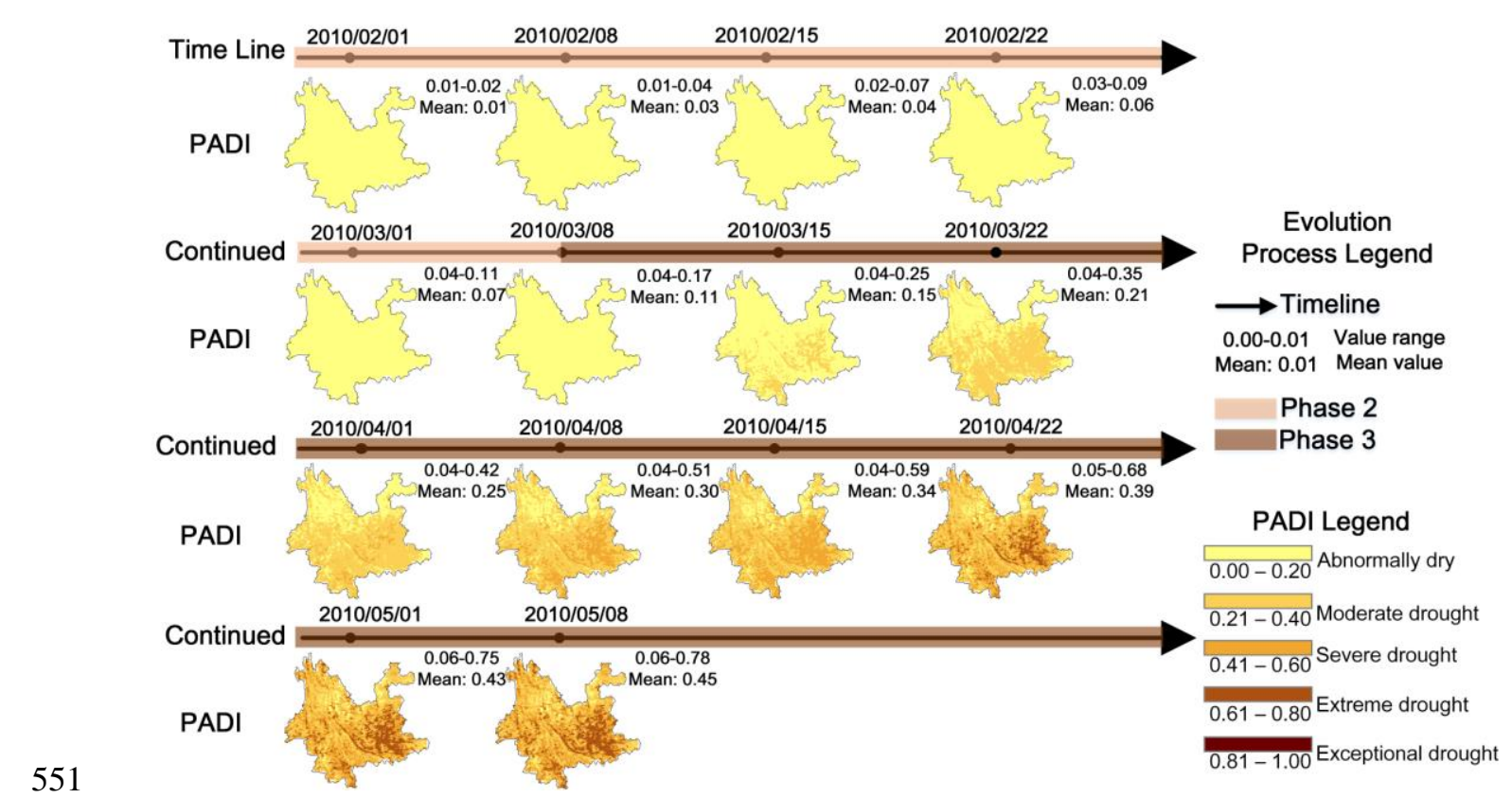

552 Figure 8. Same as Fig. 7 except for region B and time period ranging from February 2010 to

553 May 2010.

554 The 2011 drought in region $\mathrm{C}$ was much longer and more deleterious, influencing

555 different growth periods as shown in Fig. 9. Mean PADI was 0.01 at the beginning,

556 indicative of abnormally dry conditions in the study area. Moderate drought

557 emerged by early November in the central areas. By the end of December, mean

558 PADI increased to 0.21 , indicating the majority of wheat was affected by

559 moderate drought. After that, drought in the central and southern areas

560 exacerbated into a severe drought in January and February, and even to extreme

561 drought levels in March. In April, mean PADI was above 0.4, and then increased to

5620.5 in May. During the harvest in June, PADI ranged from 0.06 to 0.96 , and the

563 mean was 0.58. Drought in the southern areas had evolved into exceptional

564 drought as classified by PADI. Therefore, 2010 agricultural drought in this region

565 had significant impacts on wheat growth. 


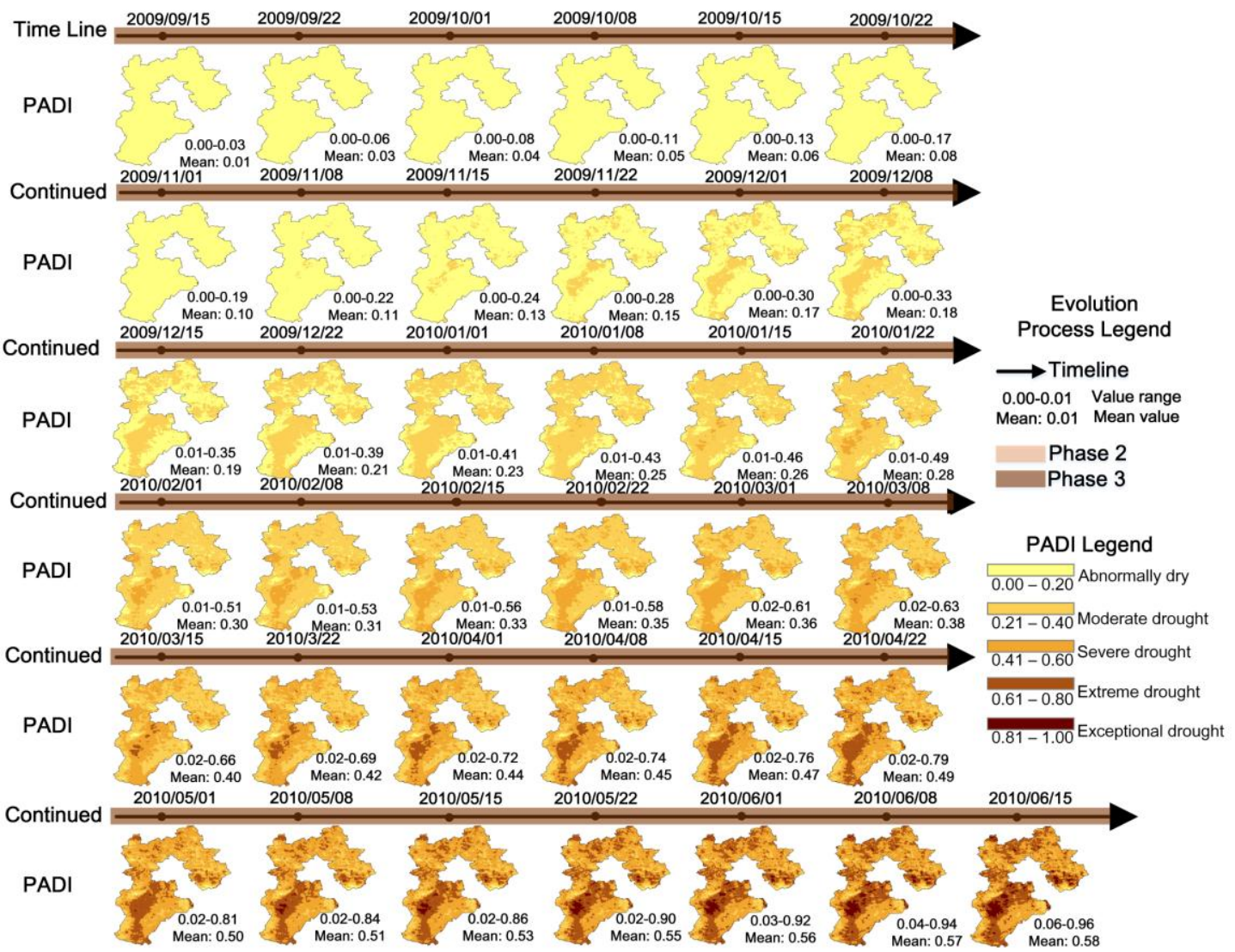

Figure 9. Same as Fig. 7 except for region C and period of September 2009 to June 2010.

In summary, the results demonstrated that PADI provides a new perspective

569 of accumulated agricultural drought severity by integrating drought evolution

570 process and crop growth. Unlike other drought index like SPI or MIDI, PADI

571 considers prior situation when quantifying subsequent severity.

572 5. Discussion

\subsection{Sensitivity analysis of crop growth and water-deficit coefficients}

The accuracy of PADI is influenced by the quality of two input crop parameters: growth stage periods $\left(s_{i}\right)$ and water-deficit sensitivity coefficients $\left(\lambda_{\mathrm{i}}\right)$. Therefore, a sensitivity analysis was undertaken to quantify the impacts of uncertainty in $s_{i}$ and $\lambda_{\mathrm{i}}$ on PADI. The nature of the sensitivity analysis used here is similar to that of Anderson et al. (1997): the absolute sensitivity (S) of any of 
the output variable $(\mathrm{V})$ to $\pm \mathrm{X}$ uncertainty in $s_{i}$ and $\lambda_{\mathrm{i}}$ was assigned as:

$$
S_{V}=\left|\left(V_{X+}-V_{X}\right) / \psi\right|
$$

where $V_{X_{+}}$and $V_{X_{-}}$are the estimated variables when the value of $s_{i}$ and $\lambda_{\mathrm{i}}$ are increased or decreased by $\mathrm{X}$, and $V_{x r}$ is the value of the estimated variable at actual $s_{i}$ and $\lambda_{1}$. In this analysis, uncertainty of $s_{i}$ was set as one-, two-, and three-weeks separately indicative of the planting date shifting by the corresponding time but by keeping the same growth length. The uncertainty of $\lambda_{\mathrm{i}}$ was set as $0.01,0.05$, and 0.1 separately, with every $\lambda$ in PADI added to this uncertainty. Results of this sensitivity analysis are shown in Fig. 10.

(a) Sensitivity by water-deficit coefficient

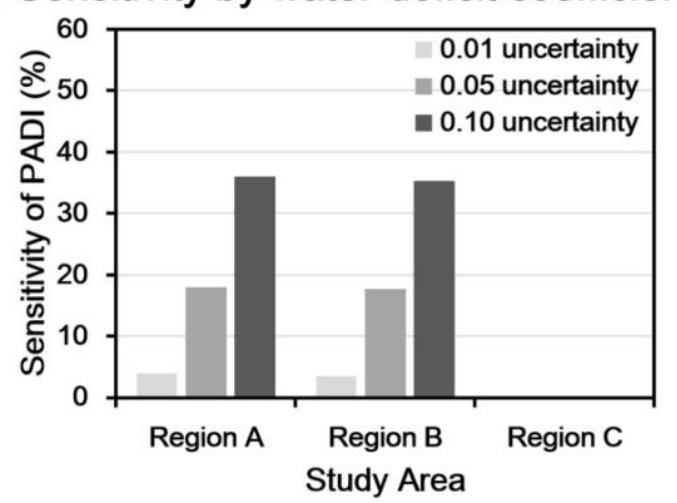

(b) Sensitivity by planting date

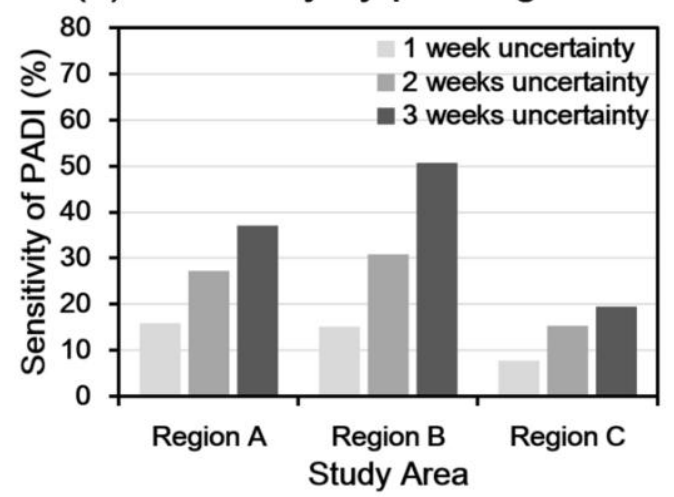

Figure 10. Sensitivity of PADI in regions A, B, and C in terms of (a) the uncertainty of 1 week,

2 weeks, and 3 weeks in planting dates of wheat, and (b) the uncertainty in water-deficit sensitivity coefficient of wheat of $0.01,0.05$, and 0.10 .

The sensitivity of PADI in all study regions exhibited a similar trend. Higher uncertainty resulted in higher PADI differences as expected. As shown in Fig. 10(a), one-week uncertainty in crop planting date led to $7.8 \%$ to $15.8 \%$ differences between their PADIs while two-weeks uncertainty corresponded to $15.3 \%$ to $30.8 \%$ variances. If there was three-weeks delay, the magnitude of PADI 
increased to $19.5 \%$ to $50.7 \%$. The increase in PADI indicates increase in the drought intensity. Comparing the three regions, it was found that region $\mathrm{A}$ and $\mathrm{B}$ was more sensitive to delay in the planting date compared region $\mathrm{C}$. This is reasonable as wheat growth time in both regions were covered by drought part time (35.0\% and $43.3 \%$ respectively). But the wheat in region $\mathrm{C}$ was fully covered by drought, so the uncertainty of crop growth had lesser influence on the final PADI calculation. As shown in Fig. 10(b), PADI was sensitive to the water-deficit sensitivity coefficient uncertainty with a magnitude of $S_{V}$ to the order of $3.9 \%-36.1 \%$ and $3.5 \%-35.4 \%$, however, no differences were found in region $\mathrm{C}$. This is due to wheat growth corresponding to the development phase of drought during which PADI took the VCI as input and not SMCI. Therefore, PADI was influenced by uncertainty in $s_{i}, \lambda_{\mathrm{i}}$, and drought developments as well. From the above analysis, it is suggested that a one week uncertainty of planting date and 0.05 uncertainty of water-deficit coefficient can be considered acceptable as the PADI sensitivity is below $20 \%$ in these conditions.

\subsection{Correlation analysis between SPI and PADI}

As PADI did not integrate precipitation deficit directly in the calculation, it is necessary to investigate differences between precipitation-based SPI and PADI. The correlation coefficients were calculated between PADI and different SPIs over all study regions for the wheat growing season, as shown in Fig. 11-13. PADI data on the 15 th of every month were selected. Pearson correlation was used here as SPI and PADI were normally distributed. Correlations varied among 
621 SPI-12 was noted and indicated the inclusiveness of PADI for short-term drought

\section{2 and long-term drought.}

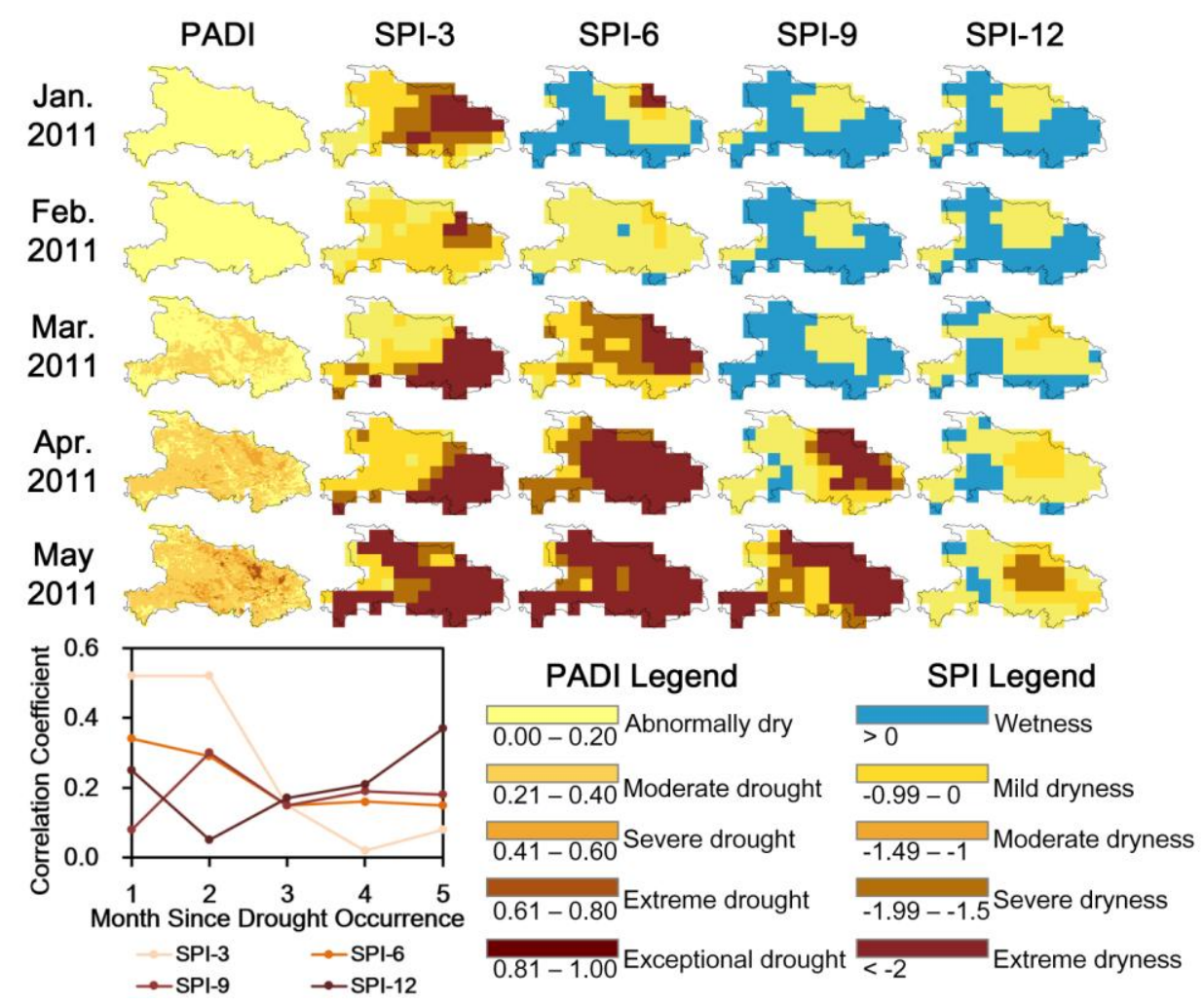

Figure 11. Correlation analysis of PADI with SPI-3, SPI-6, SPI-9, and SPI-12 from January 


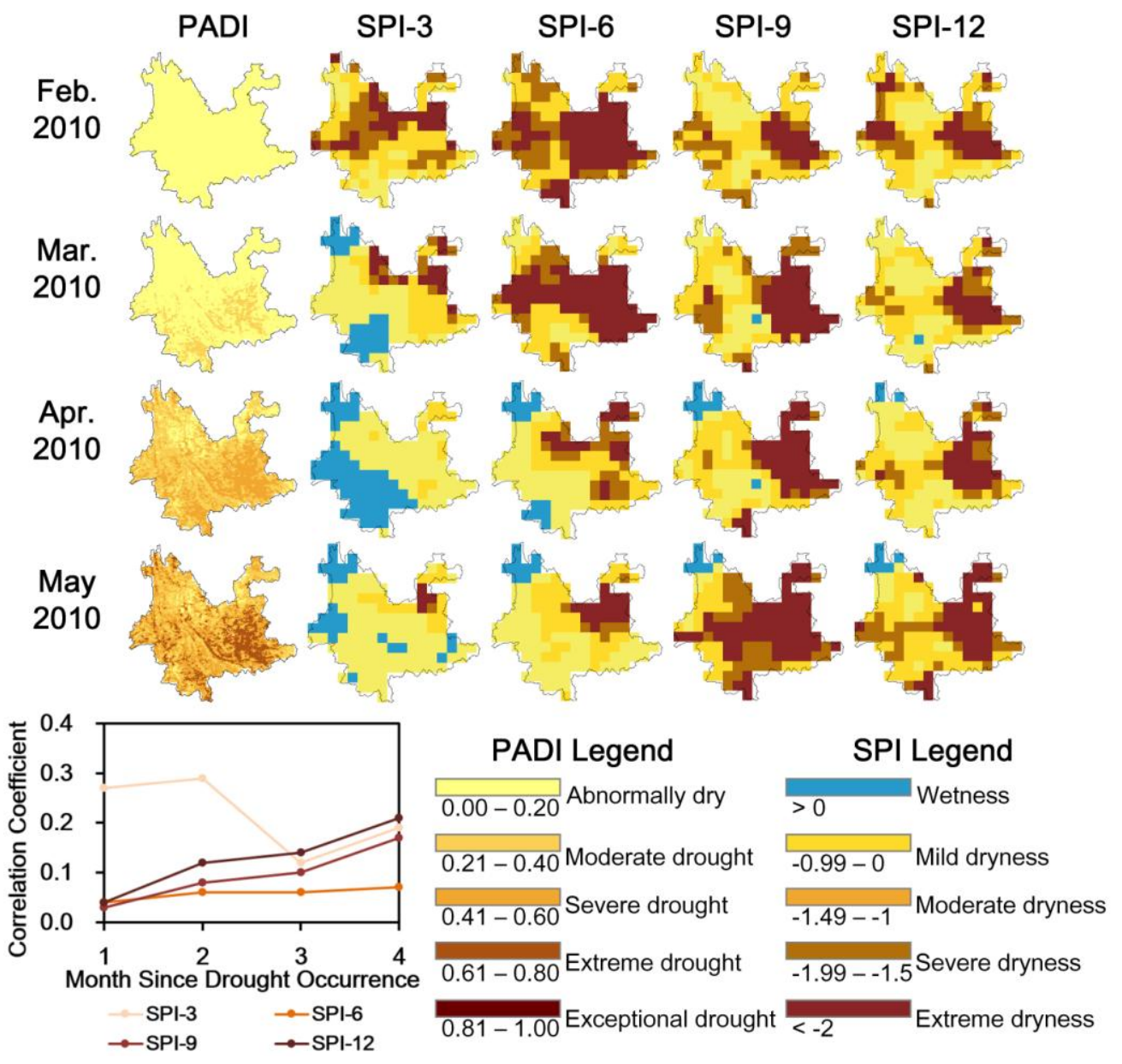

Figure 12. Same as Fig. 11 but for region B and from February 2010 to May 2010. 


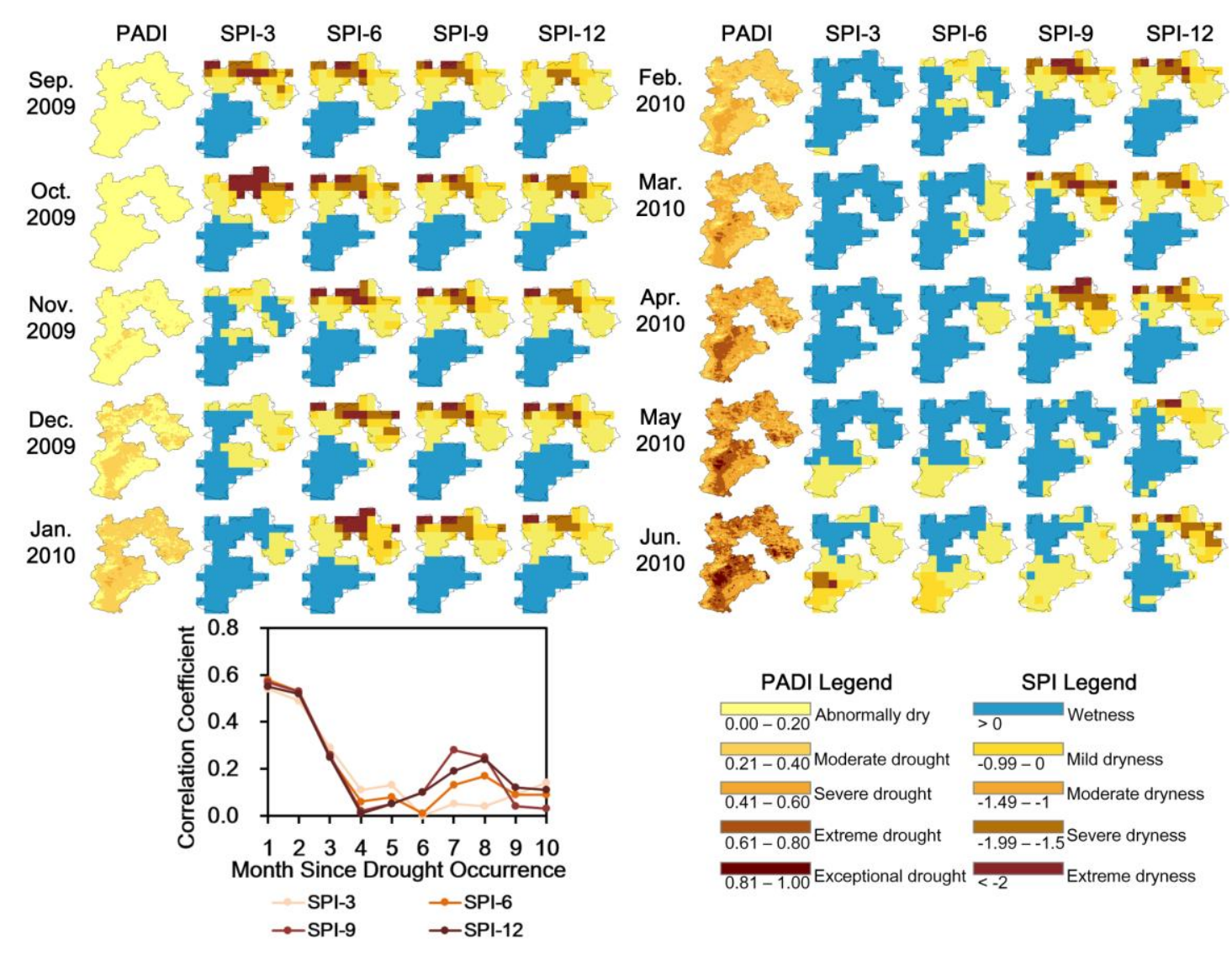

Figure 13. Same as Fig. 11 but for region C and from September 2009 to June 2010.

In region $\mathrm{A}$, PADI showed higher correlation with the 3 month SPI $(r=0.52)$

in January and February when compared with other different timescale SPIs.

632 Given the SMCI was first input into PADI in the onset phase, this result agrees

633 with the common view that 3 -month SPI reflects short- and medium-term

634 drought conditions in response to seasonal anomalies of precipitation. The

635 longer timescales of SPIs capture more enduring precipitation anomaly resulting

636 in positive SPI values except to the north of the study area (Fig. 11). In March,

637 PADI had the highest correlation with 12 month SPI (r increased from 0.17 to

638 0.37) and agreed well with SPI-12 (especially in the northern areas) as shown in

Fig. 11. This is because PADI provided the accumulated drought impacts on crops 
640 by considering the process of drought development. Therefore, it has memory of 641 the history of drought intensity. Similar to SPI-12, this feature is important to 642 evaluate long-term agricultural drought.

643 In region B, PADI showed a similar correlation having the highest agreement 644 with SPI-3 in the first two months of agricultural drought. In the last two months, 645 PADI was more related to SPI-12 ( $\mathrm{r}$ increased from 0.14 to 0.21 ). In Fig. 12, it is 646 notable that severe drought existed in the northern area and was more 647 successfully depicted by PADI, SPI-9, and SPI-12 than SPI-3 and SPI-6.

648 In region C (Fig. 13), PADI had good correlation with all SPIs, especially with 649 SPI-6 in September and October; while for the next three months, SPI-3 had higher correlations. All correlations decreased until March. In April and May, the correlations between PADI and SPI-9 and SPI-12 were the highest and the second highest, respectively.

Generally, PADI presented considerable correlation with SPI-3 and SPI-6 at the beginning of agricultural drought in all the study regions. With the evolution of drought, PADI showed a higher correlation with SPI-6 and SPI-12, also highlighting the capability of PADI in handling long-term agricultural drought.

\subsection{Comparison between PDSI and PADI}

To compare different approaches in modeling drought severity, the PDSI was compared with the PADI for each month over the three regions as shown in Fig. 


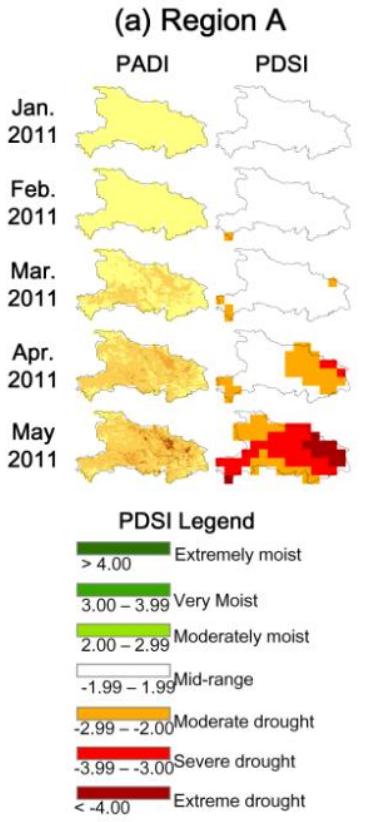

(d) Correlation in Region $\mathrm{A}$

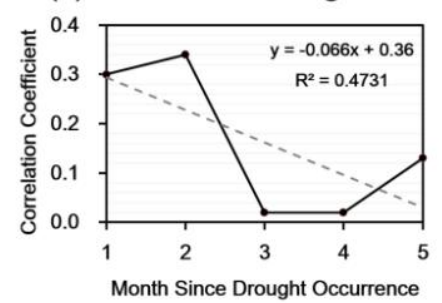

(b) Region $\mathrm{B}$

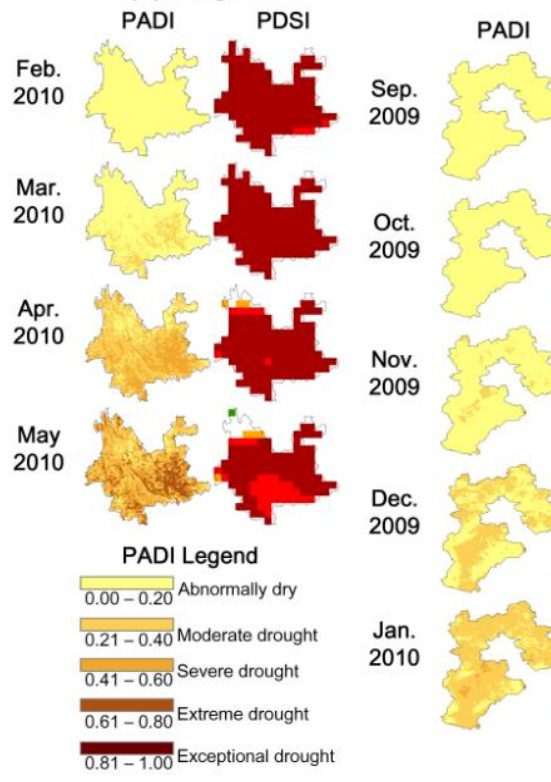

(e) Correlation in Region B

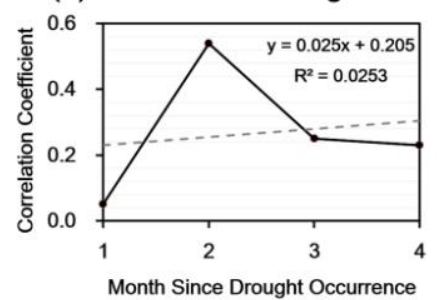

(c) Region C

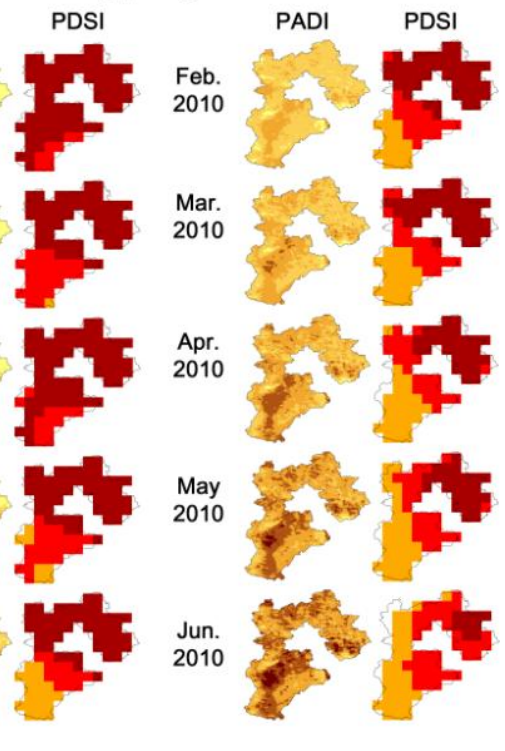

(f) Correlation in Region C

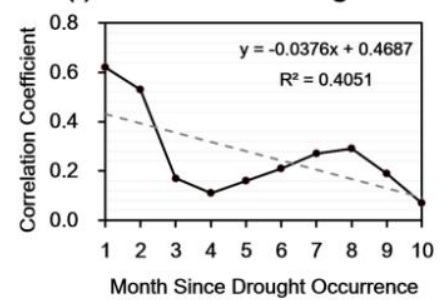

Figure 14. Comparison between PDSI and PADI in three study regions from (a) January 2011 
(a) PADI in Region A

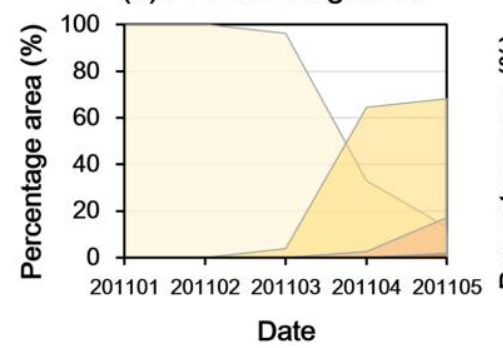

(d) PDSI in Region A

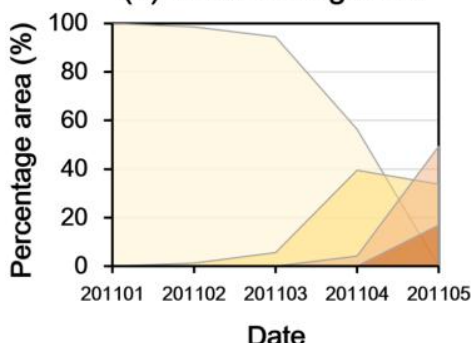

Date

PADI Legend (b) PADI in Region $B$

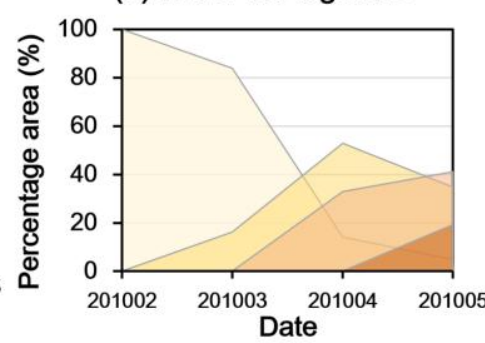

(e) PDSI in Region B

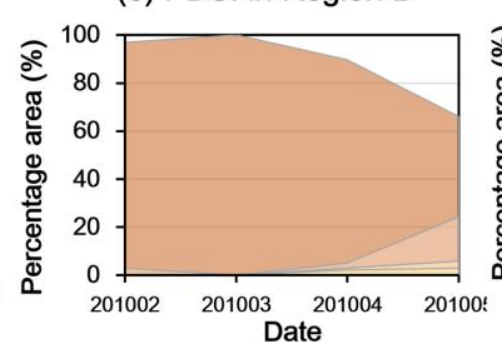

Date (c) PADI in Region C

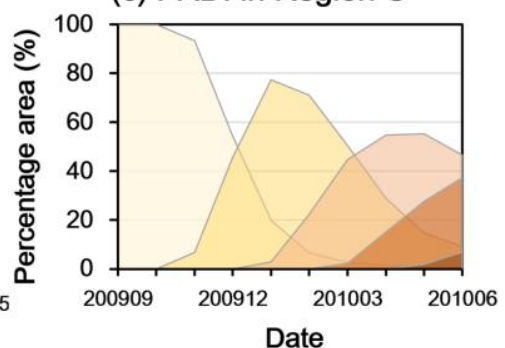

(f) PDSI in Region C

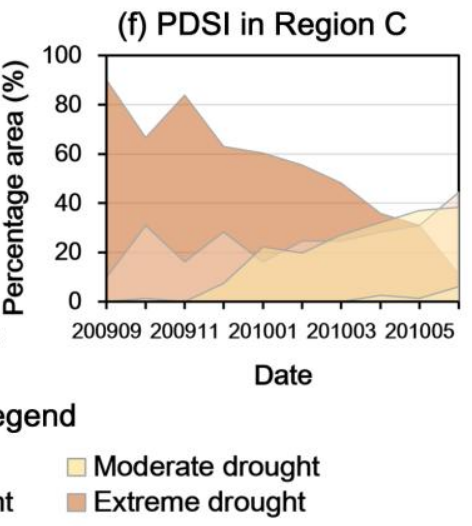

667

668

669

670

671

672

673

674

675

676

677

678

679

680

Figure 15. Comparison of percentages of different drought-affected areas between PDSI and

PADI in three study regions from (a) and (d) January 2011 to May 2011, (b) and (e)

February 2010 to May 2010, and (c) and (f) September 2009 to June 2010, respectively.

In region A (Figs. 15(a), 15(d), 16(a), and 16(d)), PADI and PDSI showed consistent spatial evluation of drought, however low correlation also indicated differernt drought severities values. From January to March, an area less than 5\% of region A was identified both by PADI and PDSI to be in moderate drought. In April, PDSI indicated moderate drought mainly covering the northeast (39\%), while PADI identified a much higher moderated drought coverage (64\%). From April to May, both PADI and PDSI demonstrated the northeast was affected most by drought: $17 \%$ severe drought by PADI and 16\% extreme drought by PDSI. At the same time, both PADI and PDSI clearly indicated the northwest of region A was impacted slightly by drought. In addition, due to the input requirements and 
681

682

683

684

685

686

687

688

689

690

691

692

693

694

695

696

697

698

699

700

701

702

data availablity, PADI provided a finer resolution $(4 \mathrm{~km})$ drought mapping compared with PDSI $\left(0.5^{\circ}\right)$. Thus, more intra-region drought details can be captured by PADI, which is helpful for microscale drought assessment.

For region B (Fig. 15(b), 15(e), 16(b), and 16(e)), PADI and PDSI showed different drought severity. According to the regional mean PDSI, moderate drought started from July 2009. So in February 2010, the whole region was considered to be over $97 \%$ under extreme drought. Based on the PADI results, agricultural drought in this region just began. This difference is derived from the treatment of all precipitation as immediately available rainfall and lack of impact of vegetation in PDSI. While in PADI, root zone soil moisture, vegetation condition, and especially crop growth stages were directly used. In addition, though both PDSI and PADI take prior drought condition into account, PADI integrates interactions between drought evolution and crop growth as well. This difference was demonstrated by variance in the severe drought areas shown in Fig. 15(b) and 15(e) by PDSI and PADI.

This difference is also obvious in region C (Fig. 15(c), 15(f), 16(c), and 16(f)). In September 2009, PDSI indicated extreme drought (90\% coverage), while PADI just began to report drought. This is related to the characteristic of PADI where crop growth stages were incorporated with environmental drought stress. So agricultural drought in PADI began with crop planting, multipled by soil moisture and vegetation severity with duration, and finally provided accumulated drought impacts until harvest. Taking the drought situation in March 2010 as an example, 
PADI indicated that a total of $90 \%$ of the area was impacted by moderate and severe drought, and the south had a more obvious severe drought. This confirms that the wheat growth in the whole region, especially in the south was mainly influenced by this drought event (also shown in Fig. A6 in the Appendix). On the contrary, PDSI showed the most extreme drought (48\%) occurred in the northeast, severe drought (25\%) in the central region, and moderate drought $(27 \%)$ in the south. This seems reasonable as precipitation and soil moisture in the northeast were indeed below average (as shown in Fig. A6). However, VCI in March actually shows vegetation in the south was in a much worse state than in the northeast. Another typical difference was noted in June, where PDSI successfully determined serious dryness at that time in the north and east. While considering the whole crop growth and drought evolution process into consideration, PADI indicated this drought was also serious in the south.

Therefore, it was found that PDSI and PADI had two different views of agricultural drought. The PDSI calculates accumulated water deficit temperature data and PET model, while the PADI directly accumulates drought severity based on soil moisture and crop conditions, in conjunction with duration and sensitivity. Therefore, while they both depict drought distribution and pattern changes, the proposed PADI gives a new and likely more direct perspective.

5.4 Correlation analysis between precipitation, soil moisture, NDVI, and PADI with wheat yield loss

A cross-correlation analysis was conducted between crop yield loss and 

coefficients $(\rho)$ were calculated. Rank correlation was chosen over Pearson correlation since the distribution of the impact data is typically not normal. Correlations were undertaken between precipitation deficit, root zone soil moisture deficit, NDVI anomaly, PADI, and wheat loss. Deficit/anomaly was obtained by averaging the PCI, SMCI, and VCI values during the agricultural drought (onset and development phases). The final PADI values shown in Fig. 7-9 were selected as it is an accumulated index. In addition, the evaluation unit here is defined as one prefecture.

(a) Yield and Precipitation

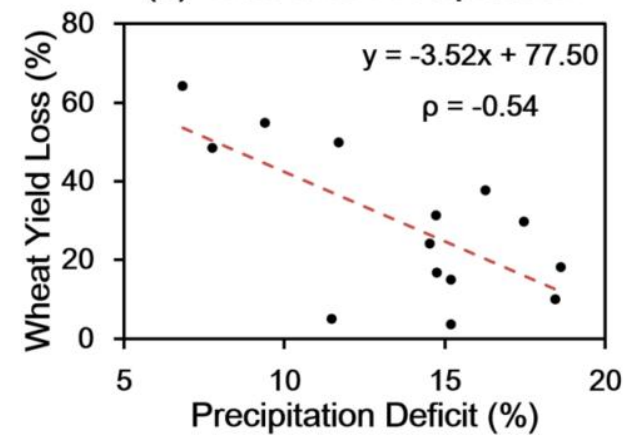

(c) Yield and Vegetation

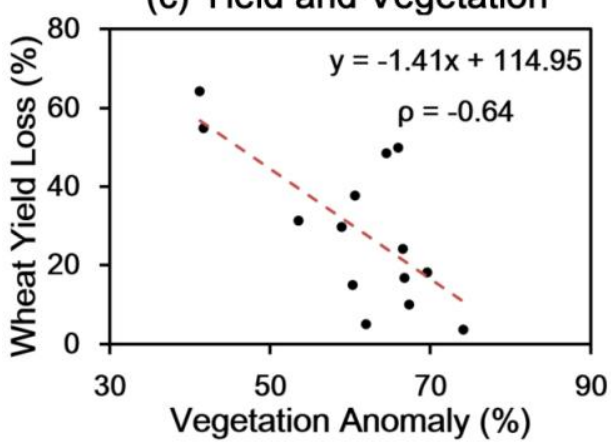

(b) Yield and Soil Moisture

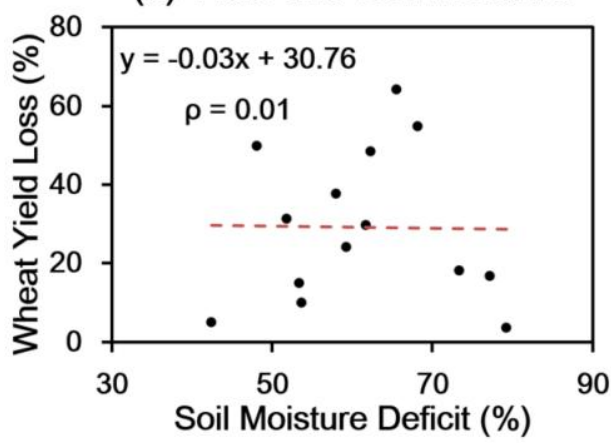

(d) Yield and PADI

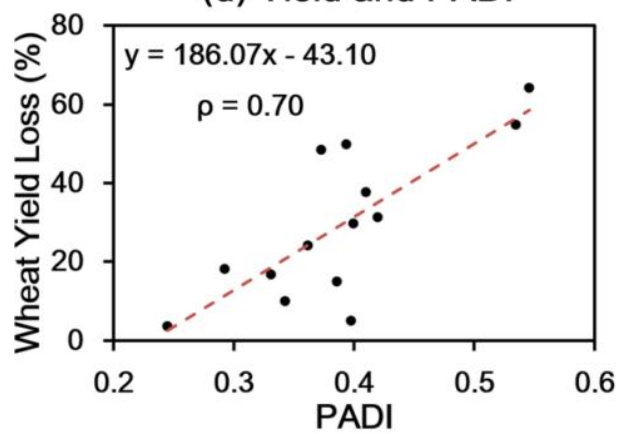

Figure 16. Scatter plot and correlation analysis between precipitation deficit, soil moisture

736 deficit, NDVI anomaly, PADI, and wheat yield loss individually for Region A in 2011. Linear

737 fitting line and an equation with the Spearman rank coefficient $(\rho)$ are given in each plot. 
(a) Yield and Precipitation

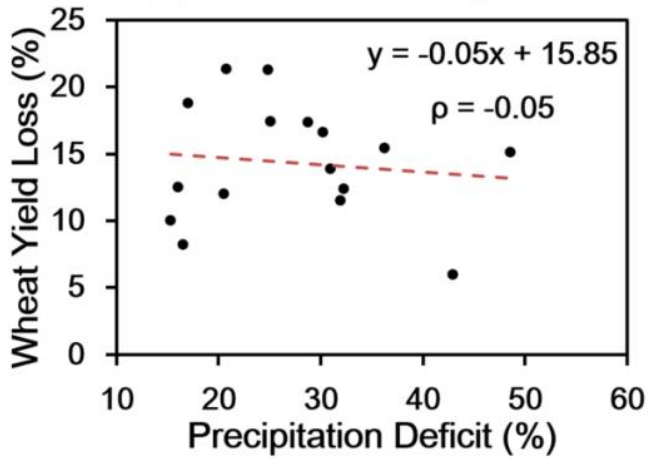

(c) Yield and Vegetation

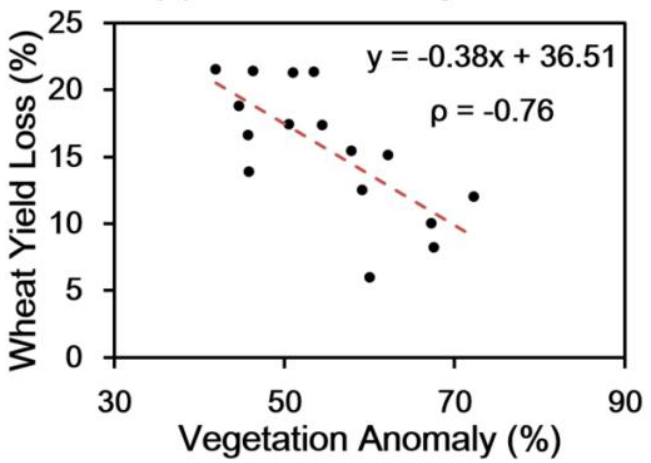

(b) Yield and Soil Moisture

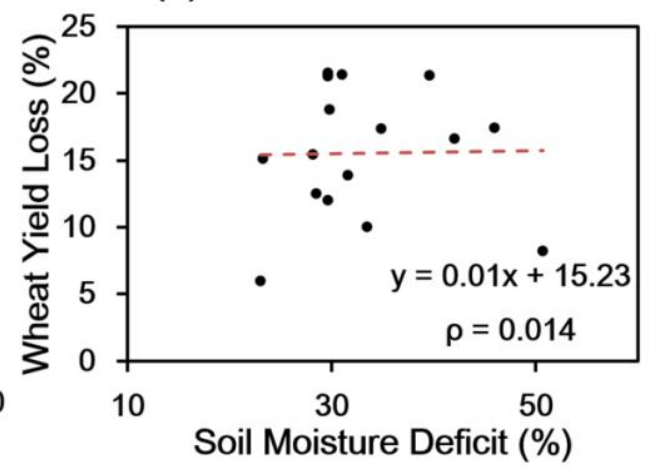

(d) Yield and PADI

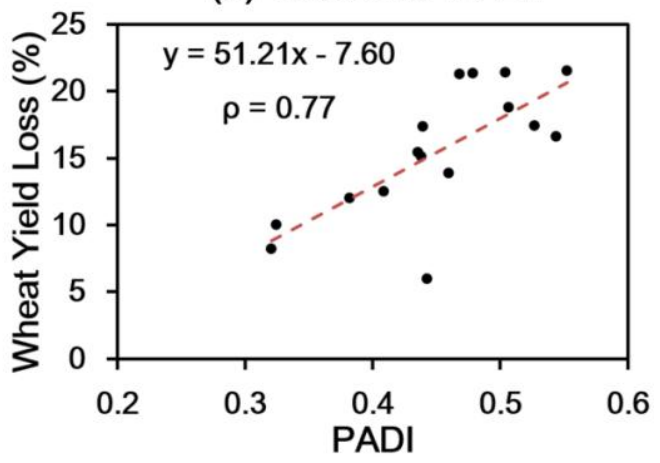

Figure 17. Same as Fig. 16 but for Region B in 2010. The size of sample (n) is 16.

(a) Yield and Precipitation

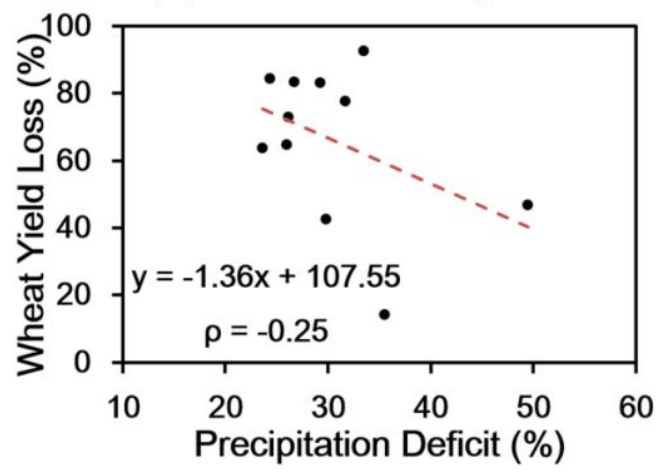

(c) Yield and Vegetation

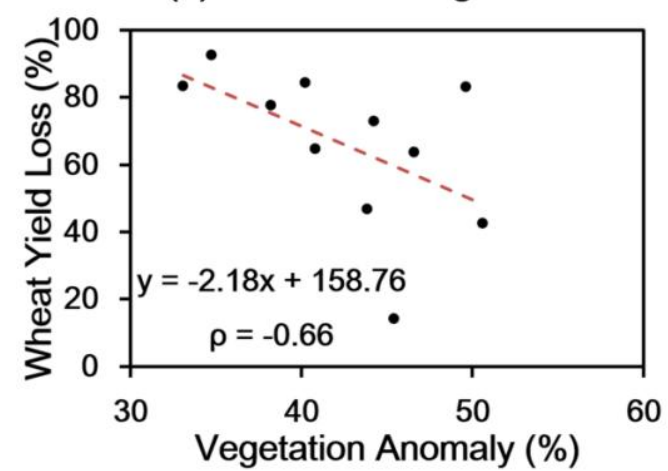

(b) Yield and Soil Moisture

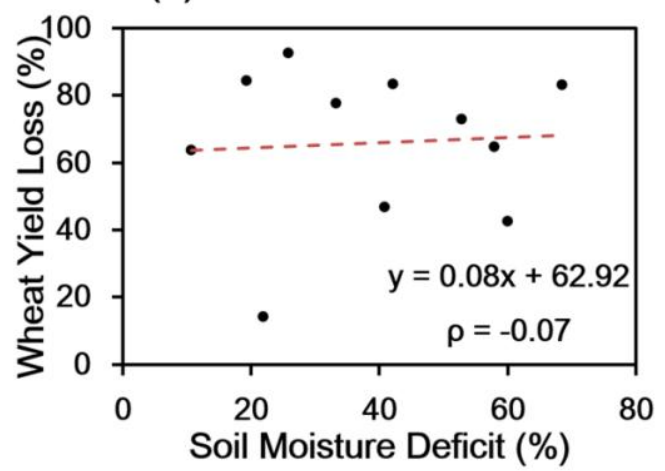

(d) Yield and PADI

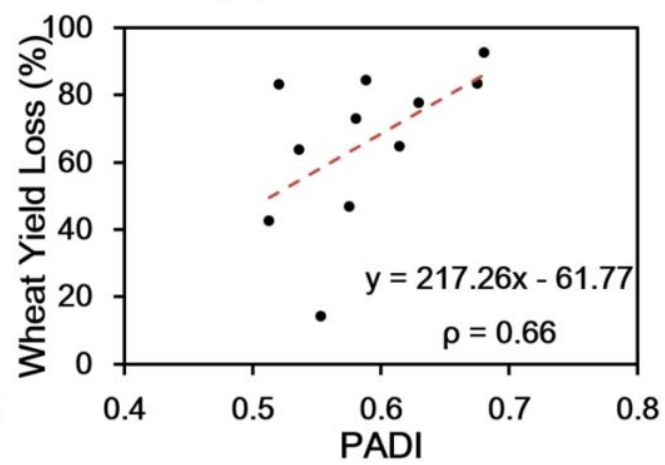

742 Figure 18. Same as Fig. 16 but for Region C in 2010. The size of sample (n) is 11. 
Based on the correlation analysis shown in Fig. 16-18, it was found that

precipitation had a modest correlation with wheat yield loss. The spearman coefficients are listed around $-0.54^{*},-0.05$, and -0.25 respectively (one superscript asterisk means $\mathrm{p}<0.05$, while two mean $\mathrm{p}<0.01$ ), and the average coefficient was -0.28 . This finding suggested precipitation deficit in Region A explained about 54\% wheat yield loss. According to Ray et al. (2015), averaged globally, precipitation variability explained $\sim 35 \%$ of wheat yield variability. Our finding agrees that as the main water input for wheat, precipitation does have a statistically weak relationship with yield. The timing of the precipitation is also an important factor therefore the rainfall amount alone need not correlate with the yield (Niyogi et al., 2015). Interestingly, the soil moisture in root zone did not have a significant correlation with yield loss in all regions ( $\rho$ was less than 0.1). The NDVI anomaly showed a close relationship with yield loss. The $\rho$ was $-0.64^{*}$, $-0.76^{* *}$, and $-0.66^{*}$ respectively, demonstrating the role of plant leaf wilting and physiology in crop yield, while the PADI had a more significant correlation with yield loss in all regions with $0.70^{* *}, 0.77^{* *}$, and $0.66^{*}$ values of $\rho$. This improvement suggested that adding the water-deficit sensitivity coefficient and duration in drought model helped calculating drought impacts, as compared to the use of soil moisture and vegetation condition alone. In other words, the different sensitivity of water stress in varying wheat stages is not considered by using only precipitation, soil moisture or vegetation alone. We conclude that to get a more accurate yield loss estimation, the combined consideration of drought 
model and crop phenology are needed. However, it is important to note that the PADI and other drought index are only indicators of the crop yield, other than a crop model. There are many factors that can influence the final crop yield, including seed variety, fertilization amount, soil characteristics, environmental parameters, and crop management decisions (Asseng et al., 2013; Kellner and Niyogi, 2015).

\subsection{Comparison with other studies}

To place the proposed drought model and results in a wider context, other studies involving bivariate/multivariate analysis for agricultural drought are revisited (Table 1). Details of these studies can be found in corresponding citations; but following key points are highlighted.

Studies such as Wilhite and Glantz (1985) recommended that a good definition of agricultural drought "should be able to account for the variable susceptibility of crops during different stages of crop development, from emergence to maturity". And the indices proposed in Du et al. (2013) and Hao and AghaKouchak (2013) highlighted that to better understand the drought processes, precipitation, soil, and vegetation conditions must be considered together with multiple sources of information. Anderson et al. (2016) also suggested that a finer crop model was needed which can consider moisture and temperature extremes during critical phenological stages of crop growth. Particularly, relevant to the study domain, Hao et al. (2015) emphasized that the drought in Southwest China should be monitored at the seasonal and regional 
level and additional distinctions of seasons and regions was needed.

Considering the above indices and recommendations, it can be highlighted that the EPMC/PADI method has the following notable features. In that, PADI is designed to be a drought-crop integrated model. Not only agricultural drought are described through four phases, their interactions with four crop growth stages were also modelled. The proposed EPMC and PADI are indeed regional specific drought monitoring framework and evaluation methodology, which integrates regional crop parameters. In addition, a weekly updated PADI map is also a potential advantage.

Despite the good performance noted in capturing drought impacts, some key limitations exist when using EPMC and PADI methods.

The inherited limitation is the data requirement. To monitor an agricultural drought comprehensively, EPMC would benefit from multi-decades ( 30 years) of datasets of precipitation, root zone soil moisture, and vegetation condition. In addition, different crop growth parameters are needed when calculating PADI, which varies regionally. Therefore, EPMC and PADI are indeed more feasible in micro to regional drought applications for regions with good data availability. We suggest that with the development of crop modeling and agricultural analysis, it is possible to get the required inputs over large spatial scales, and this will be tested in a future study.

Another limitation concerns drought duration. If under exceptional circumstances, the duration of one agricultural drought is shorter than one or 
two months (e.g., case of flash drought), the EPMC may not be able to fully depict the drought development due to the lack of high temporal resolution input data. Thus, the EPMC is potentially more suitable for medium- and long-term agricultural drought.

There is also a limitation introduced by the computation burden caused by large volume inputs and PADI design. Meanwhile, one series of PADIs only represents one kind of crop under drought stress. Therefore, different crops will need to have their own PADI even under the same drought resulting in a computational burden. This is particularly an issue for region with small and mixed farm parcels.

Indeed this is the first study of EPMC/PADI method, therefore more validation work is needed, including testing over warm semi-arid regions, comparison with the US drought monitor, and other comprehensive drought indices (e.g., VegDRI, SDI, and SDCI).

Therefore, it is emphasized that the proposed PADI is not meant to replace the currently available indicators. Rather, it should be used alongside other drought indicator.

\section{Conclusion}

This study sought answers for three key questions related to: (i) How an agricultural drought evolution can be quantified by integrating different remotely sensed datasets? (ii) How should crop growth be linked with drought impacts in a drought model? and (iii) What is the accumulative impact of drought on crops 
and how can it be assessed? To address these questions, a multi-sensor collaborating drought monitoring framework (EPMC) and drought index (PADI) were proposed together as a new agricultural drought modelling approach. EPMC combines GPCC precipitation, GLDAS soil moisture, and AVHRR vegetation data to depict the evolution of agricultural drought. Four phases, identified as the latency, onset, development, and recovery phases based on PCI, SMCI, and VCI were studied. Considering these, the phase-wise onset and termination, spatial distribution, and severity were obtained. In addition, four crop growth stages with different soil moisture deficit coefficients were analyzed. Considering the information from both drought evolution and crop phenology, the PADI model evaluated accumulated drought severity using GLDAS soil moisture and NOAA VCI datasets. This index thus captured the impact due to both drought stress and the crop vulnerability.

Applications of the PADI model in the three different regions of China with notable droughts successfully demonstrated the robustness and utility of the index. Furthermore, it was also found the PADI variance was below $20 \%$ considering an uncertainty of 1 -week in planting date and 0.05 in water stress coefficient. Comparison between multi-time scale of SPIs and PADI showed considerable correlations with the short-term SPIs for drought onset and with the long-term SPIs after that. The PADI model also had a statistically high correlation with the wheat yield loss. New perspectives regarding crop phenology integration and impact accumulation were also highlighted when 
853

854

855

856

857

858

859

860

861

862

863

864

865

866

867

868

869

870

871

872

873

874

comparing with PDSI and other existing studies. As a new accumulative drought index, PADI is not a drought "snapshot" like SPI. Therefore, PADI provides a new approach to quantify the total drought impacts on crops. This work suggest that not only should multi-variables during the agricultural drought evolution process be monitored for drought analysis but that remotely-sensed drought indicators should also be integrated with crop characteristics to obtain a more appropriate drought assessments.

\section{Acknowledgments}

This work was supported by grants from the National Basic Research Program of China (973 Program) (No. 2011CB707101), National Natural Science Foundation of China (No. 41171315), Project of Creative Research Groups of Natural Science Foundation of Hubei Province of China. Xiang was also supported by the China Scholarship Council (CSC) under the State Scholarship Fund to pursue his study at Purdue University (No. 201506270080). DN acknowledges support from NSF CAREER AGS, USDA/NIFA grant on drought triggers and global trade 2011-67019-20042 and 2015-67023-23109, USDA NIFA Hatch project 1007699. The authors also thank the following data providers: GPCC under DWD (Deutscher Wetterdienst) (http://www.dwd.de/) for providing GPCC Full Data Reanalysis Version 7 precipitation data; Matthew Rodell and Hiroko Kato Beaudoing, NASA/GSFC/HSL for providing GLDAS data (http://ldas.gsfc.nasa.gov/gldas/); NOAA center for Satellite Applications and 

providing PDSI data (http://www.cgd.ucar.edu/cas/catalog/climind/pdsi.html); Amir AghaKouchak in UC Irvine for providing the Standardized Drought Analysis Toolbox (SDAT) to calculate SPI. The authors also wish to thank the anonymous reviewers and the Associate Editor for their valuable and useful suggestions that clearly improved this paper. We thank Dallas Staley for her professional help in editing the paper.

References

Abbas, S., Nichol, J., Qamer, F., \& Xu, J. (2014). Characterization of Drought 
two-source time-integrated model for estimating surface fluxes using thermal infrared remote sensing. Remote Sensing of Environment, 60, 195-216

Anderson, M.C., Zolin, C.A., Sentelhas, P.C., Hain, C.R., Semmens, K., Tugrul Yilmaz, 

Analysis of Drought Variability and Impacts. Bulletin of the American Meteorological Society, 91, 1351-1356

Bi, H., Ma, J., Zheng, W., \& Zeng, J. (2016). Comparison of soil moisture in GLDAS model simulations and in situ observations over the Tibetan Plateau. Journal of Geophysical Research: Atmospheres, 121, 2658-2678

Brown, J.F., Wardlow, B.D., Tadesse, T., Hayes, M.J., \& Reed, B.C. (2013). The Vegetation Drought Response Index (VegDRI): A New Integrated Approach for Monitoring Drought Stress in Vegetation. GIScience \& Remote Sensing, 45, $16-46$

Changnon, S.A., \& Easterling, W.E. (1989). Measuring Drought Impacts: The Illinois Case. JAWRA Journal of the American Water Resources Association, 25, $27-42$

Charusombat, U., \& Niyogi, D. (2011). A Hydroclimatological Assessment of Regional Drought Vulnerability: A Case Study of Indiana Droughts. Earth Interactions, 15, 1-65

Chen, Y., Yang, K., Qin, J., Zhao, L., Tang, W., \& Han, M. (2013). Evaluation of AMSR-E retrievals and GLDAS simulations against observations of a soil moisture network on the central Tibetan Plateau. Journal of Geophysical Research: Atmospheres, 118, 4466-4475

Chen, H., Jia, G., Feng, J., Dong, Y., \& Zhang, A. (2014). Monitoring Global Land Surface Drought Severity by Multi-Sensors Remote Sensing Data. Chinese 
Dai, A. (2011). Characteristics and trends in various forms of the Palmer Drought Severity Index during 1900-2008. Journal of Geophysical Research: Atmospheres, 116, 1-26

Dai, A. (2013). Increasing drought under global warming in observations and models. Nature Climate Change, 3, 52-58

Dai, A., Trenberth, K.E., \& Qian, T. (2004). A Global Dataset of Palmer Drought Severity Index for 1870-2002: Relationship with Soil Moisture and Effects of Surface Warming. Journal of Hydrometeorology, 5, 1117-1130

Dorigo, W., de Jeu, R., Chung, D., Parinussa, R., Liu, Y., Wagner, W., \& Fernández-Prieto, D. (2012). Evaluating global trends (1988-2010) in harmonized multi-satellite surface soil moisture. Geophysical Research Letters, 39, 1-7

Dracup, J.A. (1991). Drought monitoring. Stochastic Hydrology and Hydraulics, 5, $261-266$

Du, L., Tian, Q., Yu, T., Meng, Q., Jancso, T., Udvardy, P., \& Huang, Y. (2013). A comprehensive drought monitoring method integrating MODIS and TRMM data. International Journal of Applied Earth Observation and Geoinformation, $23,245-253$

Estrela, T., \& Vargas, E. (2012). Drought Management Plans in the European Union. The Case of Spain. Water Resources Management, 26, 1537-1553

Farahmand, A., \& AghaKouchak, A. (2015). A generalized framework for deriving 

nonparametric standardized drought indicators. Advances in Water Resources, 76, 140-145

Farahmand, A., AghaKouchak, A., \& Teixeira, J. (2015). A Vantage from Space Can Detect Earlier Drought Onset: An Approach Using Relative Humidity. Scientific

Ghulam, A., Qin, Q., Teyip, T., \& Li, Z.-L. (2007). Modified perpendicular drought

Guanter, L., Zhang, Y., Jung, M., Joiner, J., Voigt, M., Berry, J.A., Frankenberg, C., Huete, A.R., Zarco-Tejada, P., Lee, J.-E., Moran, M.S., Ponce-Campos, G., Beer, C., Camps-Valls, G., Buchmann, N., Gianelle, D., Klumpp, K., Cescatti, A., Baker, J.M., \& Griffis, T.J. (2014). Global and time-resolved monitoring of crop photosynthesis with chlorophyll fluorescence. Proceedings of the National Academy of Sciences, 111, E1327-E1333

Hao, Z., \& AghaKouchak, A. (2013). Multivariate Standardized Drought Index: A parametric multi-index model. Advances in Water Resources, 57, 12-18

Hao, Z., \& AghaKouchak, A. (2014). A Nonparametric Multivariate Multi-Index Drought Monitoring Framework. Journal of Hydrometeorology, 15, 89-101

Hao, Z., AghaKouchak, A., Nakhjiri, N., \& Farahmand, A. (2014). Global integrated drought monitoring and prediction system. Scientific Data, 1, 140001

Hao, C., Zhang, J., \& Yao, F. (2015). Combination of multi-sensor remote sensing data for drought monitoring over Southwest China. International Journal of 
Heim, R.R., \& Brewer, M.J. (2012). The Global Drought Monitor Portal: The Foundation for a Global Drought Information System. Earth Interactions, 16,

Hobbins, M.T., Dai, A., Roderick, M.L., \& Farquhar, G.D. (2008). Revisiting the

Kao, S.-C., \& Govindaraju, R.S. (2010). A copula-based joint deficit index for droughts. Journal of Hydrology, 380, 121-134

Kellner, O., \& Niyogi, D. (2015). Climate Variability and the U.S. Corn Belt: ENSO and AO Episode-Dependent Hydroclimatic Feedbacks to Corn Production at Regional and Local Scales. Earth Interactions, 19, 1-32

Kogan, F.N. (2002). World droughts in the new millennium from AVHRR-based vegetation health indices. Eos, Transactions American Geophysical Union, 83, $557-563$

Kogan, F., Yang, B., Wei, G., Zhiyuan, P., \& Xianfeng, J. (2005). Modelling corn production in China using AVHRR - based vegetation health indices. International Journal of Remote Sensing, 26, 2325-2336

Li, R., Tsunekawa, A., \& Tsubo, M. (2013). Index-based assessment of agricultural drought in a semi-arid region of Inner Mongolia, China. Journal of Arid Land, 
Liu, S., Zhang, Y., Zhang, Y., \& Ding, Y. (2009). Estimation of glacier runoff and future trends in the Yangtze River source region, China. Journal of Glaciology, $55,353-362$

Liu, X., Luo, Y., Yang, T., Liang, K., Zhang, M., \& Liu, C. (2015). Investigation of the probability of concurrent drought events between the water source and destination regions of China's water diversion project. Geophysical Research Letters, 42, 8424-8431

Liu, Y., Pan, Z., Zhuang, Q., Miralles, D.G., Teuling, A.J., Zhang, T., An, P., Dong, Z., Zhang, J., He, D., Wang, L., Pan, X., Bai, W., \& Niyogi, D. (2015). Agriculture intensifies soil moisture decline in Northern China. Scientific Reports, 5, 11261

Lyon, B., Bell, M.A., Tippett, M.K., Kumar, A., Hoerling, M.P., Quan, X.-W., \& Wang, H. (2012). Baseline Probabilities for the Seasonal Prediction of Meteorological Drought. Journal of Applied Meteorology and Climatology, 51, 1222-1237

Maity, R., Ramadas, M., \& Govindaraju, R.S. (2013). Identification of hydrologic drought triggers from hydroclimatic predictor variables. Water Resources Research, 49, 4476-4492

Mallya, G., Zhao, L., Song, X.C., Niyogi, D., \& Govindaraju, R.S. (2013). 2012 Midwest Drought in the United States. Journal of Hydrologic Engineering, 18, 737-745

Matthias, Z., Luis, S., Rohini, K., Stephan, T., Juliane, M., David, S., \& Andreas, M. 

074002

1031

1032

1033

1034

1035

1036

1037

1038

1039

1040

1041

1042

1043

1044

1045

1046

1047

1048

1049

1050

McKee, T.B., Doesken, N. J., \& Kleist J. (1993). The relationship of drought frequency and duration of time scales. Eighth Conference on Applied Climatology, American Meteorological Society, Jan17-23, 1993, Anaheim CA, 179-186

McVicar, T.R., \& Bierwirth, P.N. (2001). Rapidly assessing the 1997 drought in Papua New Guinea using composite AVHRR imagery. International Journal of Remote Sensing, 22, 2109-2128

McVicar, T.R., \& Jupp, D.L.B. (1998). The current and potential operational uses of remote sensing to aid decisions on drought exceptional circumstances in Australia: a review. Agricultural Systems, 57, 399-468

Miller, T. D. (1992). Growth stages of wheat. Better crops with plant food. Potash \& Phosphate Institute, 76, 12

Mishra, A.K., \& Singh, V.P. (2010). A review of drought concepts. Journal of Hydrology, 391, 202-216

Mishra, A.K., \& Singh, V.P. (2011). Drought modeling - A review. Journal of Hydrology, 403, 157-175

Mueller, B., \& Seneviratne, S.I. (2012). Hot days induced by precipitation deficits at the global scale. Proceedings of the National Academy of Sciences, 109, 12398-12403

National Bureau of Statistics of the People's Republic of China (2015). 2015 
National Bureau of Statistics on food production announcement. http://www.stats.gov.cn/tjsj/zxfb/201512/t20151208_1286449.html

National Drought Mitigation Center. Types of Drought. http://drought.unl.edu/DroughtBasics/TypesofDrought.aspx

National Weather Service NOAA (2008). What is Drought Why is Drought

Palmer, W. C. (1965). Meteorological Drought. U.S. Weather Research Paper 45.

Niyogi, D., \& Raman, S. (1997). Comparison of four different stomatal resistance schemes using FIFE observations. Journal of Applied Meteorology, 36(7), 903-917.

Rajsekhar, D., Singh, V.P., \& Mishra, A.K. (2015a). Multivariate drought index: An information theory based approach for integrated drought assessment. Journal of Hydrology, 526, 164-182

Rajsekhar, D., Singh, V.P., \& Mishra, A.K. (2015b). Hydrologic Drought Atlas for Texas. Journal of Hydrologic Engineering, 20, 05014023

Ray, D.K., Gerber, J.S., MacDonald, G.K., \& West, P.C. (2015). Climate variation explains a third of global crop yield variability. Nature Communication, 6, 
1074

1075

1076

1077

1078

1079

1080

1081

1082

1083

1084

1085

1086

1087

1088

1089

1090

1091

1092

1093

1094

Rhee, J., Im, J., \& Carbone, G.J. (2010). Monitoring agricultural drought for arid and humid regions using multi-sensor remote sensing data. Remote Sensing of Environment, 114, 2875-2887

Rodell, M., Houser, P.R., Jambor, U., Gottschalck, J., Mitchell, K., Meng, C.-J., Arsenault, K., Cosgrove, B., Radakovich, J., Bosilovich, M., Entin, J.K., Walker, J.P., Lohmann, D., \& Toll, D. (2004). The Global Land Data Assimilation System. Bulletin of the American Meteorological Society, 85, 381-394

Schneider, U., Becker, A., Finger, P., Meyer-Christoffer, A., Rudolf, B., Ziese, M. (2015). GPCC Full Data Reanalysis Version 7.0 at $0.5^{\circ}$ : Monthly Land-Surface Precipitation from Rain-Gauges built on GTS-based and Historic Data

Sheffield, J., Wood, E.F., Chaney, N., Guan, K., Sadri, S., Yuan, X., Olang, L., Amani, A., Ali, A., Demuth, S., \& Ogallo, L. (2014). A Drought Monitoring and Forecasting System for Sub-Sahara African Water Resources and Food Security. Bulletin of the American Meteorological Society, 95, 861-882

Sheffield, J., Wood, E.F., \& Roderick, M.L. (2012). Little change in global drought over the past 60 years. Nature, $491,435-438$

Spennemann, P.C., Rivera, J.A., Saulo, A.C., \& Penalba, O.C. (2015). A comparison of GLDAS soil moisture anomalies against standardized precipitation index and multisatellite estimations over South America. Journal of Hydrometeorology, $16,158-171$

Su, Z., Yacob, A., Wen, J., Roerink, G., He, Y., Gao, B., Boogaard, H., \& van Diepen, C. 

(2003). Assessing relative soil moisture with remote sensing data: theory, experimental validation, and application to drought monitoring over the North China Plain. Physics and Chemistry of the Earth, Parts A/B/C, 28,

Svoboda, M., LeComte, D., Hayes, M., Heim, R., Gleason, K., Angel, J., Rippey, B.,

model. http://www.pecad.fas.usda.gov/highlights/2009/04/ChinaDrought/ChinaWinterWheatGrowthS tageModel.htm

Verdin, J., Funk, C., Senay, G., \& Choularton, R. (2005). Climate science and famine early warning. Philosophical Transactions of the Royal Society of London B: Biological Sciences, 360, 2155-2168

Vicente-Serrano, S.M., Beguería, S., \& López-Moreno, J.I. (2010). A Multiscalar Drought Index Sensitive to Global Warming: The Standardized Precipitation Evapotranspiration Index. Journal of Climate, 23, 1696-1718

Wang, W., Guo, L., Li, Y., Su, M., Lin, Y., de Perthuis, C., Ju, X., Lin, E., \& Moran, D. (2014). Greenhouse gas intensity of three main crops and implications for low-carbon agriculture in China. Climatic Change, 128, 57-70

Wang, X.H., Qiao, Y.F., Shen, R.K., Yin, Z.J., \& Hu, T.S. (2004). Drought risk 
Wells, N., Goddard, S., \& Hayes, M.J. (2004). A Self-Calibrating Palmer Drought Severity Index. Journal of Climate, 17, 2335-2351

Wilhite, D.A. (1993). Drought Assessment, Management, and Planning: Theory and Case Studies. Boston: Springer Science + Business Media, 1-290

Wilhite, D.A. (2000). Chapter 1 Drought as a Natural Hazard- Concepts and Definitions. London: Routledge, 3-18

Wilhite, D.A., \& Glantz, M.H. (1985). Understanding the Drought Phenomenon:

The Role of Definitions. Water International, 10, 111-120

Wilhite, D.A., Svoboda, M.D., \& Hayes, M.J. (2007). Understanding the complex impacts of drought: A key to enhancing drought mitigation and preparedness. Water Resources Management, 21, 763-774

Wu, J., Zhou, L., Liu, M., Zhang, J., Leng, S., \& Diao, C. (2013). Establishing and assessing the Integrated Surface Drought Index (ISDI) for agricultural drought monitoring in mid-eastern China. International Journal of Applied Earth Observation and Geoinformation, 23, 397-410

Wu, J., Zhou, L., Mo, X., Zhou, H., Zhang, J., \& Jia, R. (2015). Drought monitoring and analysis in China based on the Integrated Surface Drought Index (ISDI). International Journal of Applied Earth Observation and Geoinformation, 41, 23-33

Yang, X., Tang, J., Mustard, J.F., Lee, J.-E., Rossini, M., Joiner, J., Munger, J.W., Kornfeld, A., \& Richardson, A.D. (2015). Solar-induced chlorophyll 
fluorescence that correlates with canopy photosynthesis on diurnal and seasonal scales in a temperate deciduous forest. Geophysical Research Letters, $42,2977-2987$

Yan, H., Wang, S.-Q., Wang, J.-B., Lu, H.-Q., Guo, A.-H., Zhu, Z.-C., Myneni, R.B., \& Shugart, H.H. (2016). Assessing spatiotemporal variation of drought in China and its impact on agriculture during 1982-2011 by using PDSI indices and

Yu, M., Li, Q., Hayes, M.J., Svoboda, M.D., \& Heim, R.R. (2014). Are droughts $4394-4401$

Zargar, A., Sadiq, R., Naser, B., \& Khan, F.I. (2011). A review of drought indices. 
Zhang, A., \& Jia, G. (2013). Monitoring meteorological drought in semiarid regions using multi-sensor microwave remote sensing data. Remote Sensing of Environment, 134, 12-23

Zhang, J., Sun, F., Xu, J., Chen, Y., Sang, Y.-F., \& Liu, C. (2016). Dependence of trends in and sensitivity of drought over China (1961-2013) on potential and average monthly precipitation are shown. 
1183

1184

1185

1186

1187

1188

1189

1190

1191

1192

1193

Figure 2. The flowchart of EPMC and the basic evolution process of agricultural drought that includes latency, onset, development, and recovery phases. Regardless of whether irrigated or rainfall agriculture, these four phases represent the anomaly transformation from precipitation to available soil moisture and to vegetation stress. The EPMC combines GPCC, GLDAS, and AVHRR datasets/sensors to identify these phases (shown on the right side). PCI (Precipitation Condition Index), SMCI (Soil Moisture Condition Index), and VCI (Vegetation Condition Index) are used to quantify anomalies of precipitation, soil moisture, and vegetation separately. It is emphasized that as long as the variable orders and indices remain unchanged, the remote sensors/dataset used in EPMC could be replaced by similar ones.

Figure 3. The schematic diagram of PADI. On the left, EPMC divides the agricultural drought into four evolution phases using PCI, SMCI, and VCI indices. On the right, there are three typical crop growth phases to show their different interactions with the drought. For every crop growth case, different growth stages were divided to represent different soil water sensitivity. In this paper, we consider the widely cultivated wheat in the study area as an example, so there are tillering, booting, florescence, and pustulation stages. The grey bars indicate different calculation spans of PADI, which is the common period of the drought onset phase and the development phase with crop growth. The divisions of the PADI grey bar represent the changes of parameters when calculated, since the drought phase or water-deficit sensitivity is changed at that time.

Figure 4. Mean and standard deviations of PCI, SMCI, and VCI under the EPMC framework in 
region A. This plot is organized on a timeline from September 2010 to June 2011. PCI and SMCI were obtained monthly, while VCI was updated weekly. The inflection denotes a new drought phase starting at that point of time. Four phases are marked in different colors.

Figure 5. Same as Fig. 4 except for region B. This plot is organized on a timeline from September 2009 to August 2010.

Figure 6. Same as Fig. 4 except for region C, and corresponding to a timeline of August 2009 to July 2010.

Figure 7. Agricultural drought severity mapping using PADI for region A. This result is shown by a timeline from the start to the end of agricultural drought, which is from January 2011 to May 2011. The onset and development phases are also marked in two colors above the timeline. PADI maps were updated weekly with their ranges, means, and classifications.

Figure 8. Same as Fig. 7 except for region B and time period ranging from February 2010 to May 2010.

Figure 9. Same as Fig. 7 except for region C and period of September 2009 to June 2010.

Figure 10. Sensitivity of PADI in regions A, B, and C in terms of (a) the uncertainty of 1 week, 2 weeks, and 3 weeks in planting dates of wheat, and (b) the uncertainty in water-deficit 
sensitivity coefficient of wheat of $0.01,0.05$, and 0.10 .

Figure 11. Correlation analysis of PADI with SPI-3, SPI-6, SPI-9, and SPI-12 from January 2011 to May 2011 in region A. The absolute value of correlation coefficient is shown here.

Figure 12. Same as Fig. 11 but for region B and from February 2010 to May 2010.

Figure 13. Same as Fig. 11 but for region C and from September 2009 to June 2010.

Figure 14. Comparison between PDSI and PADI in three study regions from (a) January 2011 to May 2011, (b) February 2010 to May 2010, and (c) September 2009 to June 2010, respectively, with correlation coefficients shown in (d)-(f).

Figure 15. Comparison of percentages of different drought-affected areas between PDSI and PADI in three study regions from (a) and (d) January 2011 to May 2011, (b) and (e) February 2010 to May 2010, and (c) and (f) September 2009 to June 2010, respectively.

Figure 16. Scatter plot and correlation analysis between precipitation deficit, soil moisture deficit, NDVI anomaly, PADI, and wheat yield loss individually for Region A in 2011. Linear fitting line and an equation with the Spearman rank coefficient $(\rho)$ are given in each plot. The size of sample (n) is 14 . 
Figure 17. Same as Fig. 16 but for Region B in 2010. The size of sample (n) is 16.

Figure 18. Same as Fig. 16 but for Region C in 2010. The size of sample (n) is 11

Appendix it was compared with the widely used NASA GIMMS DNVI. They were scaled to

At present, there are several satellite NDVI datasets, including SPOT NDVI, MODIS NDVI, $1^{\text {st }}$ and $3^{\text {rd }}$ generation of National Aeronautics and Space Administration (NASA) Global Inventory Modeling and Mapping Studies (GIMMS) NDVI, and The Center for Satellite Applications and Research (STAR) of NOAA NDVI. As the temporal coverage of SPOT and MODIS NDVI ranges from 1998 and 2000 respectively, the length of data record is typically shorter than a common climatological research length of 30 years. Therefore, these two NDVI datasets were not selected in this study.

In terms of NASA GIMMS NDVI and NOAA STAR NDVI dataset, temporal resolution is one of their main differences: bi-weekly vs. weekly. In addition, $4 \mathrm{~km}$ spatial resolution of NOAA STAR NDVI is also finer than $8 \mathrm{~km}$ of NASA GIMMS NDVI. Therefore, NOAA STAR NDVI was selected as it can provide fine spatial-temporal variations of vegetation condition, which is desired to quantify the severity of a local drought event.

To validate the input NOAA STAR NDVI dataset, from which VCI was deduced, the same spatial resolution of $0.125^{\circ}$ and a temporal resolution of bi-weekly 
1271 spanning the time period 1981 to 2013. Ten sampling pointes were selected 1272 randomly in the study area for evaluation. First, NASA GIMMS NDVI values with 1273 NOAA STAR NDVI values were plotted separately and as a whole to investigate 1274 their numerical relationship, shown in the Figure A1. Spearman correlation 1275 coefficients $(\rho)$ shown in these ten points ranged from 0.74 to 0.92 , with the 1276 mean value of 0.86 . The value of $\rho$ was 0.80 when considering all NDVI values. All $1277 \mathrm{p}$ values were less than 0.01. Based on that, it was concluded that the NASA 1278 GIMMS NDVI is highly correlated NOAA STAR NDVI. However, all slopes were 1279 smaller than 1 (mean slope value was 0.48), indicating NOAA STAR NDVI is 1280 consistently lower than NASA GIMMS NDVI. 


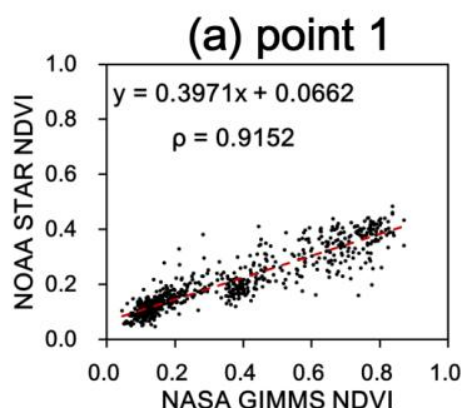

(d) point 4

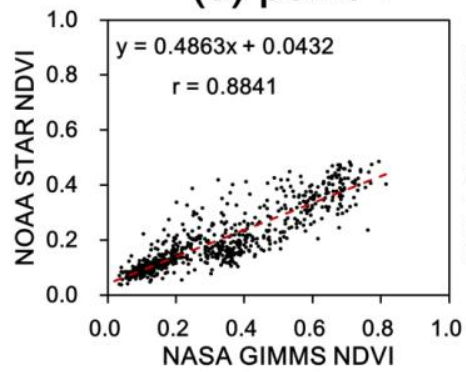

(g) point 7

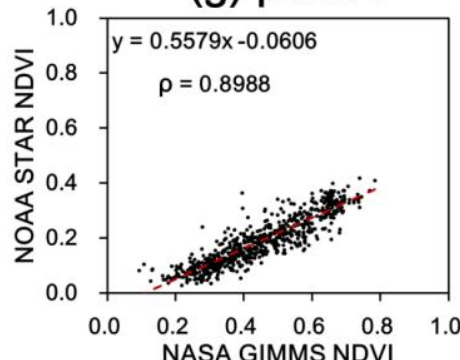

(j) point 10

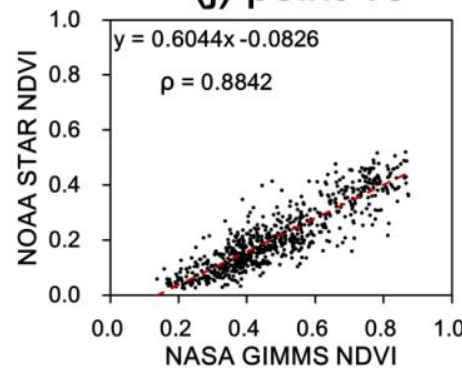

(b) point 2

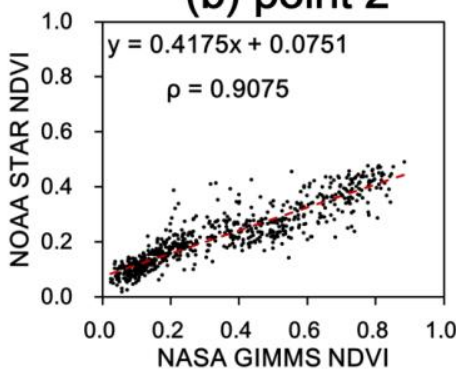

(e) point 5

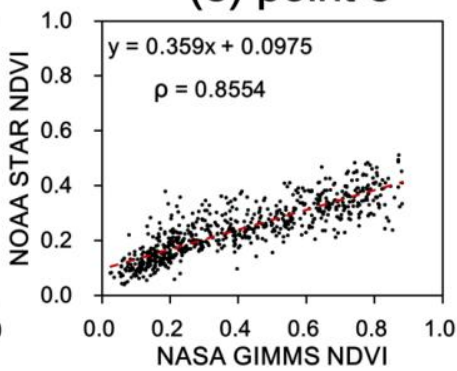

(h) point 8

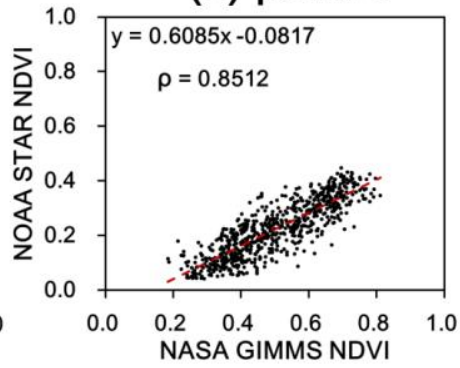

(k) all ten points

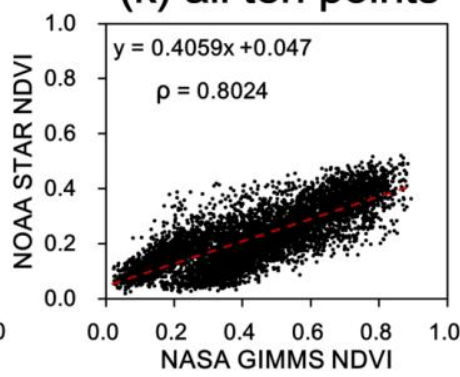

Figure A1. Spearman correlation between NOAA STAR NDVI and NASA GIMMS NDVI datasets in different locations respectively and as a whole. Data span from 1981 to 2013 in a bi-weekly manner. Linear regression line, equation, and spearman correlation coefficients were also provided. The size of sample (n) is 707 for (a) - (j).

Temporal variations in Figure A2 also demonstrated the significantly correlated relationship between these two NDVI datasets. Their differences in the absolute value of NDVI were also obvious, which corresponded with the slope values in Figure A1. Due to similar variation pattern, only three points were 
selected here.
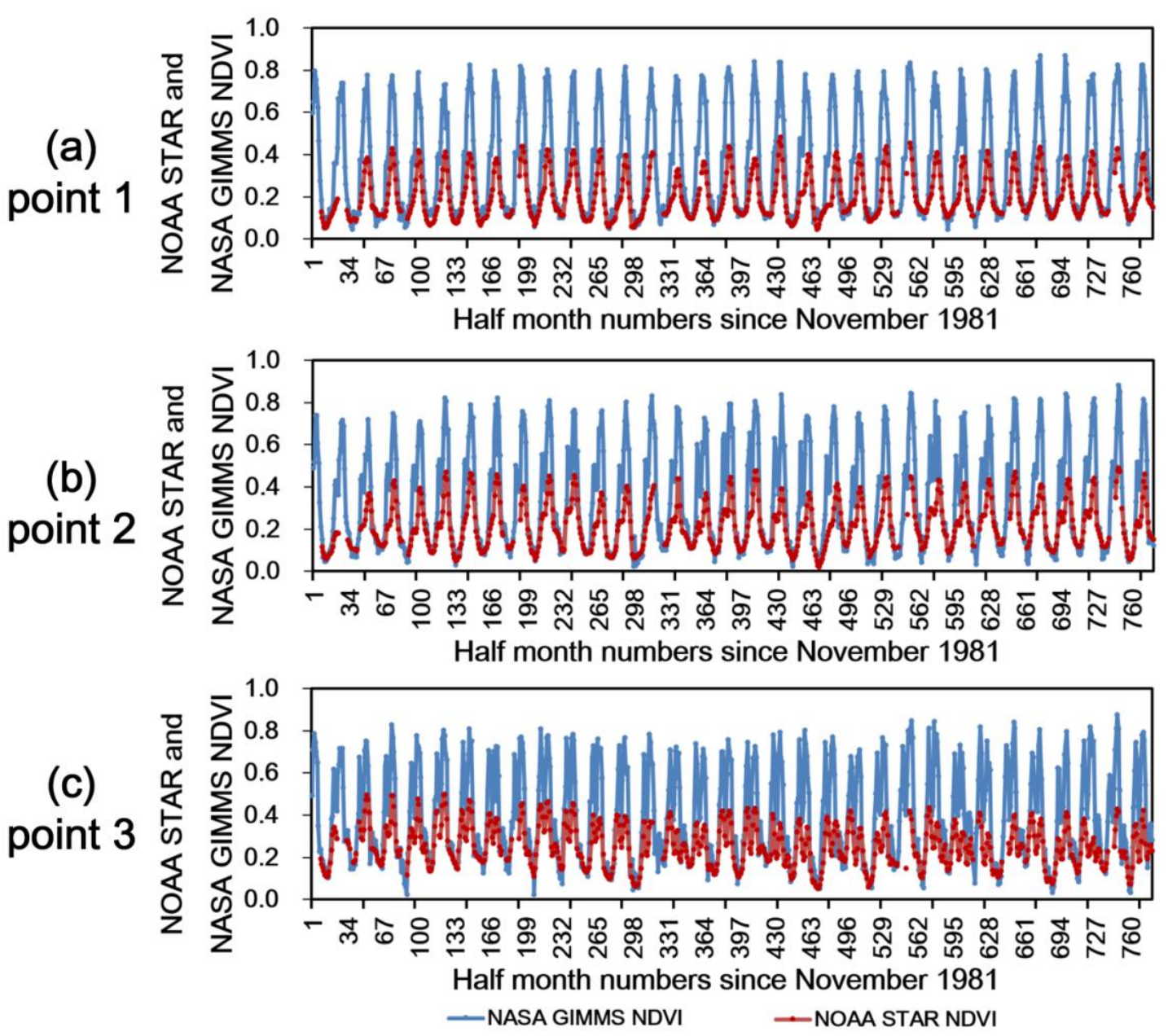

1292 Figure A2. Temporal variations between NOAA STAR NDVI and NASA GIMMS NDVI datasets

in three locations respectively and as a whole. Data span from 1981 to 2013 in a bi-weekly manner.

The VCI used in this study is a relative NDVI condition based on long-term historical NDVI data. Therefore, it is the relative variations, not the absolute values, of NDVI that were used to determine the values of VCI. The above analyses demonstrated the highly correlated relationship between these two NDVI dataset. Therefore, it can be deduced that the VCI value of these two datasets will likely be in good agreement. 
compared with one-month scale SPI (SPI-1) separately and as a whole, shown in Figure A3. Monthly mean values of PCI and SPI-1 in each region were selected, spanning from 2010-2011, 2008-2010, and 2006-2010, respectively. Based on the Kolmogorov-Smirnov test (K-S test) with alpha of 0.05 , they are normally distributed. So Pearson correlation coefficient was used here. Based on the results, it was found that PCI and SPI-1 were significantly correlated, independent of time and location. The overall linear correlation coefficient between PCI and SPI-1 is 0.86 . The similarity in slopes and intercepts indicate this relationship is relatively stable. Therefore, it is concluded that PCI has comparable capability with SPI-1 in quantifying precipitation deficit.

(a) Region A
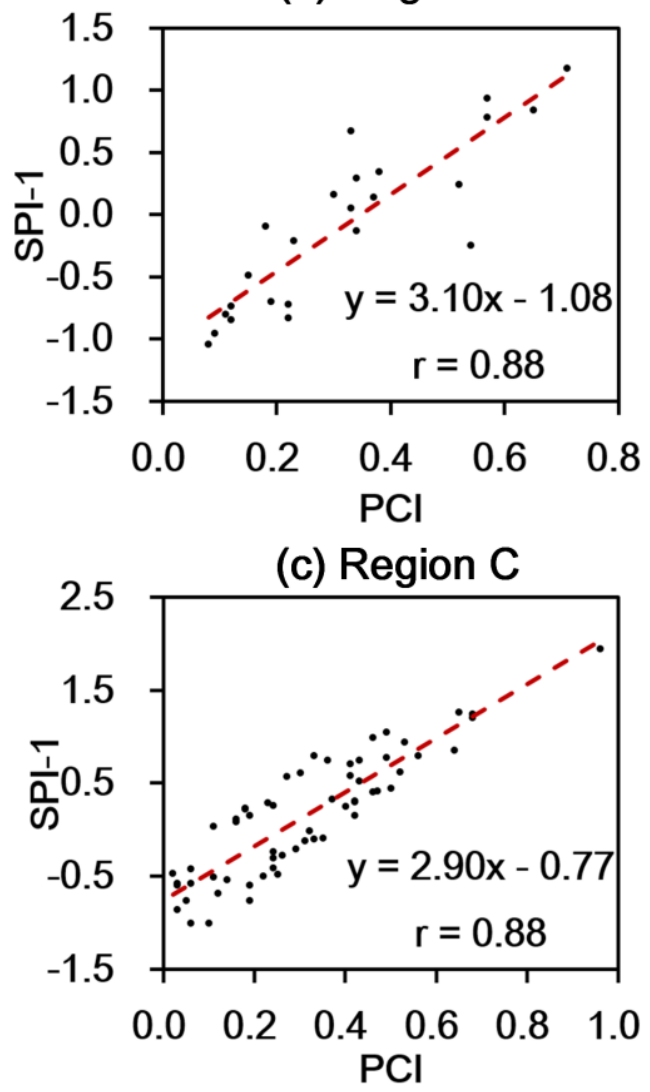

(b) Region B

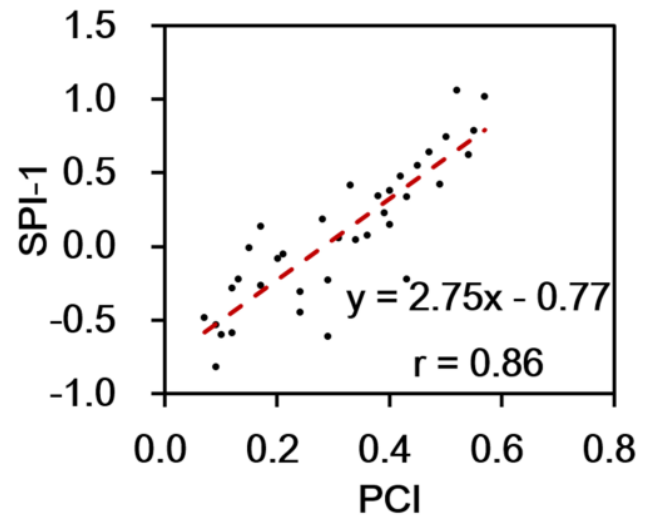

(c) All Regions

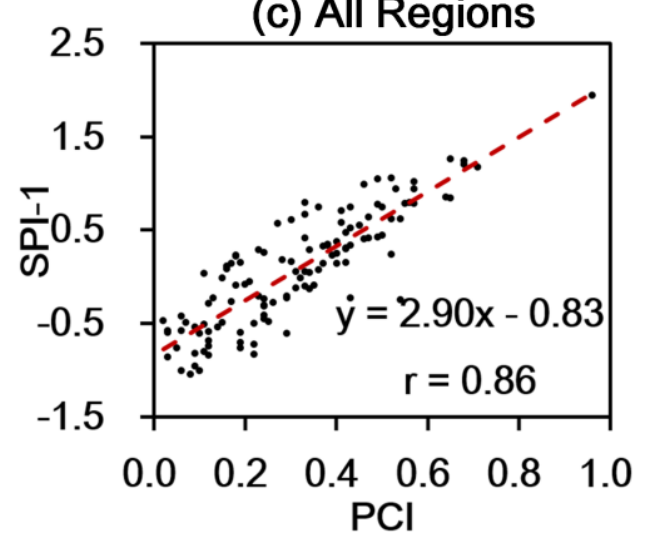

Figure A3. Correlation analysis between monthly mean PCI and SPI-1 in study region A, B, C 
separately and as a whole. PCI and SPI-1 data span 2010-2011, 2008-2010, and 2006-2010,

By comparing occurrences of drought determined by PCI and SPI-1 respectively in Table A1, it was found that PCI agreed with SPI for about $60 \%$ conditions, while PCI was 38\% more likely to identify a drought event. This

1320 statistical analysis indicated discrepancy in PCI and SPI in categorizing drought 1321 and non-drought situation, but for most periods, they agreed with each other 1322 well. It is difficult and also beyond the scope of this study to identify which one categorized drought better, because there is no independent dataset to compare 1324 against. What can be highlighted is that based on PCI, the latency phase was 1325 successfully detected in this study. Given that, it is concluded that PCI is useful for 1326 this study. In addition, the consistent relationship between PCI and SPI as 1327 demonstrated indicated that their discrepancy is likely linked to the different 1328 approaches to consider precipitation distribution and the threshold used in 1329 drought categorizing. Here, threshold is 0.5 for PCI and 0 for SPI.

\section{Table A1}

1331 Counts of drought identified by PCI and SPI separately.

\begin{tabular}{cccc}
\hline Counts & Droughts in PCI & Non-droughts in PCI & Total \\
\hline Droughts in SPI & 53 & 1 & 54 \\
Non-droughts in SPI & 47 & 19 & 66 \\
Total & 100 & 20 & 120 \\
\hline
\end{tabular}


1333 the details of PCI, SMCI, and VCI in the three regions.

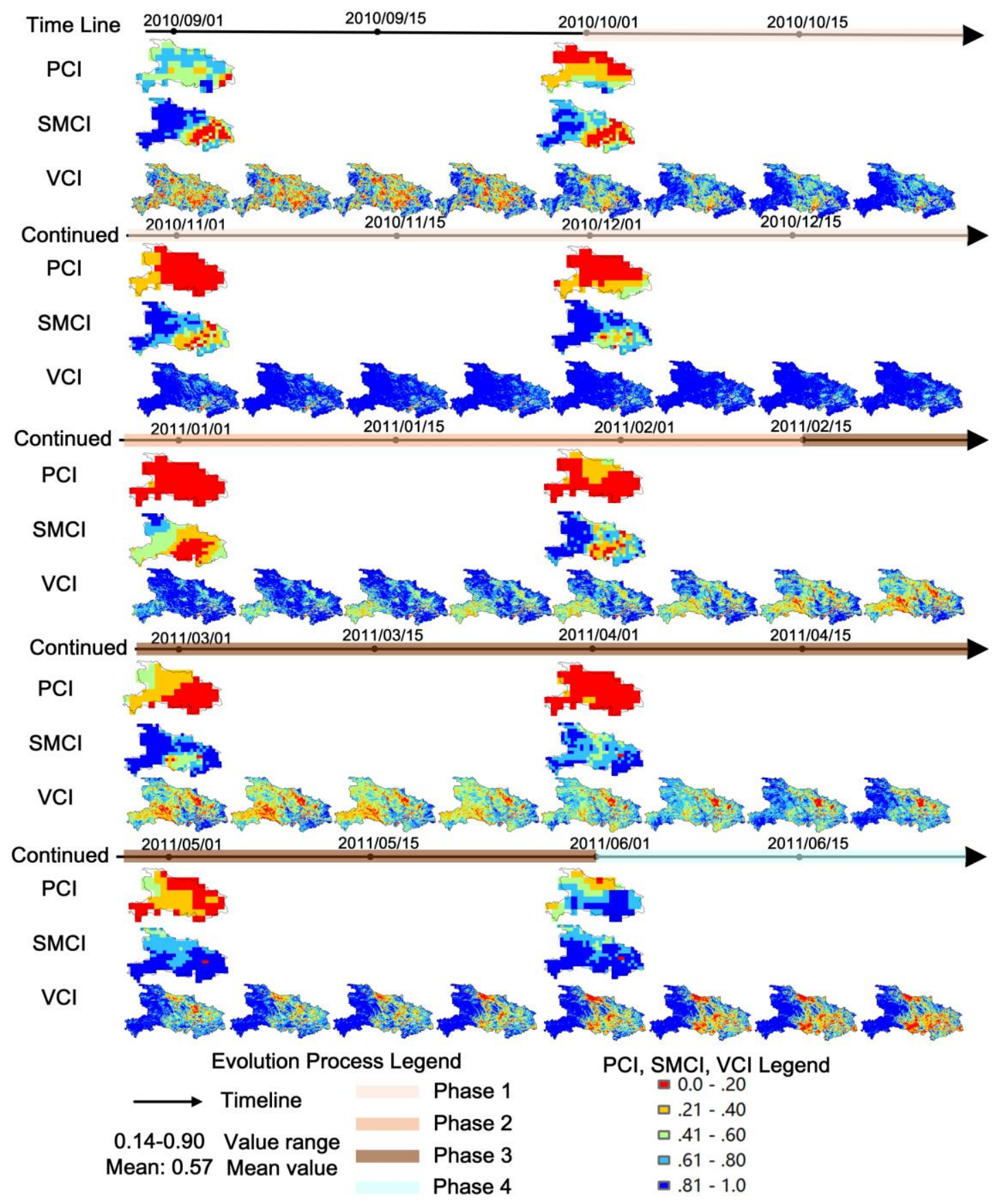

Figure A4. Spatial evolution of PCI, SMCI, and VCI under the EPMC framework in Hubei province, China. This result is organized on a timeline from September 2010 to June 2011. PCI and SMCI were obtained monthly, while VCI was refreshed weekly. Different agricultural drought evolution processes are also marked in different colors above the timeline. 


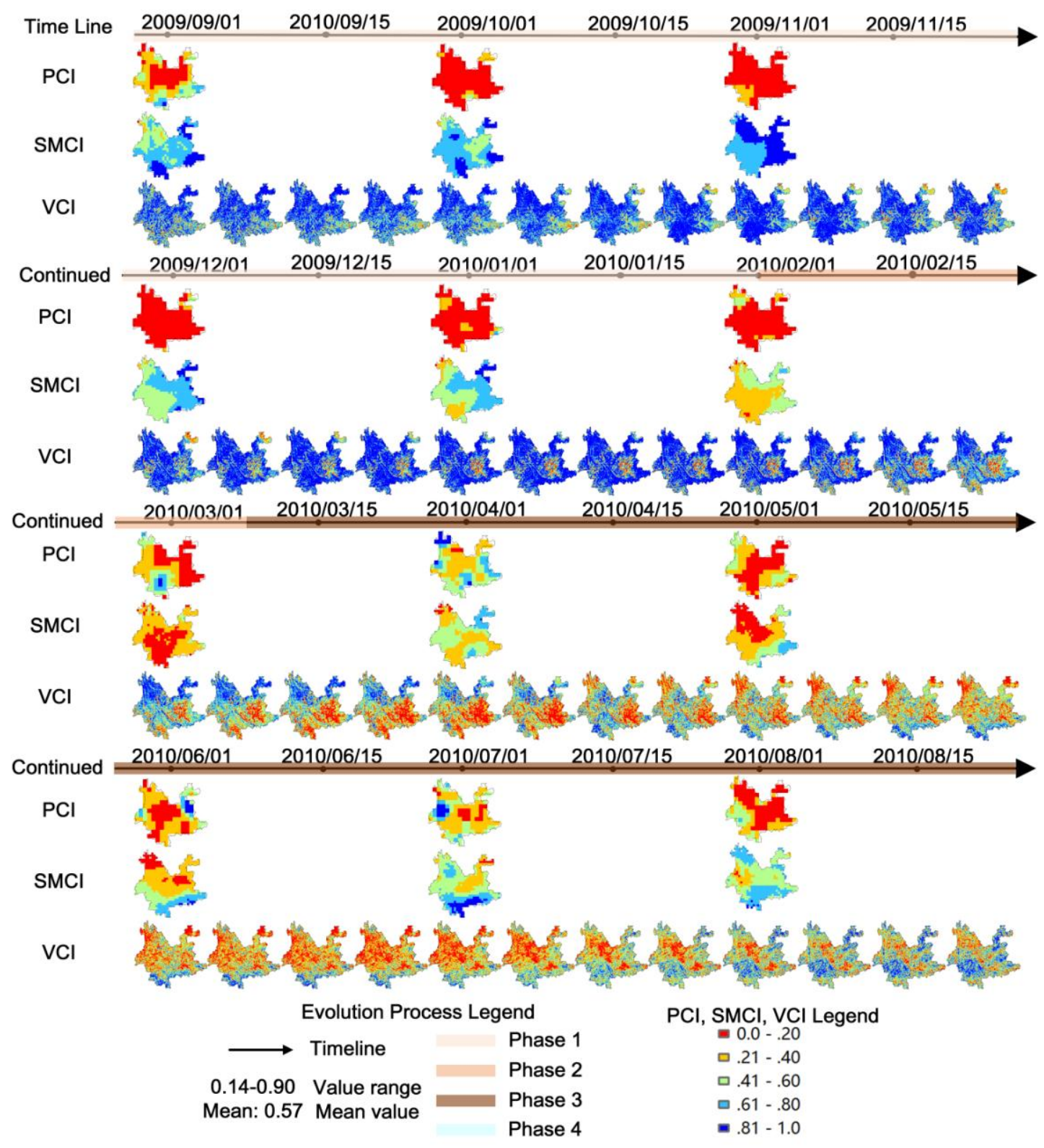

1340 Figure A5. Same with Figure A4, but in Yunnan province from September 2009 to August 13412010. 


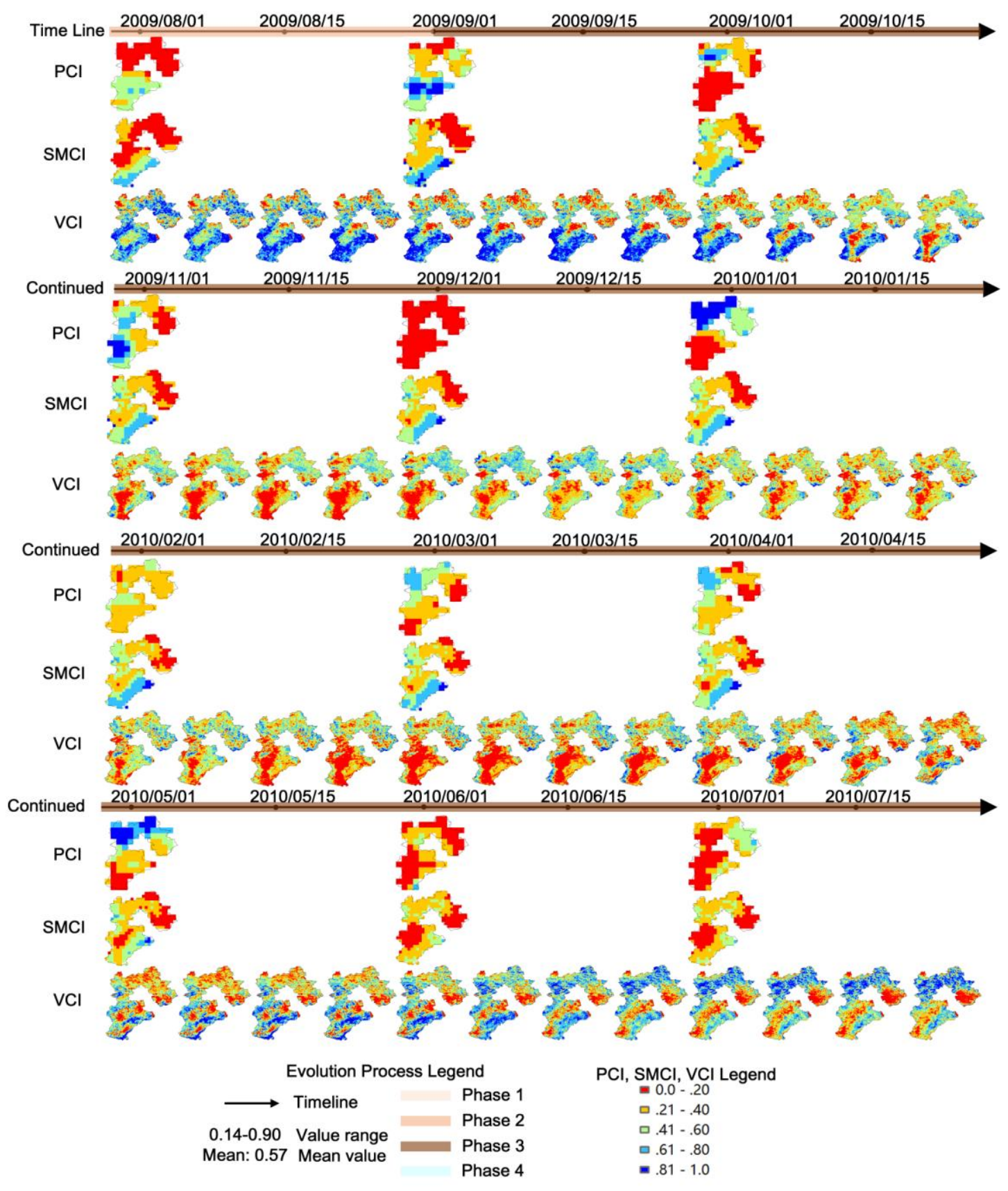

Figure A6. Same with Figure A4, but in Hebei province from August 2009 to July 2010. 